\title{
The Analysis of the Spatiotemporal Variations and Mechanisms for the Near-Surface Wind Speed Over China in the Last 40 Years
}

\section{Xia Li}

Northwest Institute of Eco-Environment and Resources https://orcid.org/0000-0002-1413-6668

Yongjie Pan ( $\sim$ panyongjie@lzb.ac.cn )

Northwest Institute of Eco-Environment and Resources

\section{Yingsha Jiang}

Northwest Institute of Eco-Environment and Resources

\section{Research Article}

Keywords: Near-surface wind speed, Wind speed trend, Mechanism of wind speed variation, China

Posted Date: November 10th, 2021

DOl: https://doi.org/10.21203/rs.3.rs-932142/v1

License: (c) (i) This work is licensed under a Creative Commons Attribution 4.0 International License.

Read Full License

Version of Record: A version of this preprint was published at Theoretical and Applied Climatology on March 3rd, 2022. See the published version at https://doi.org/10.1007/s00704-022-03991-z. 


\section{Abstract}

Near-surface wind speed is of great significance in many aspects of the human production and living. This study analyses the spatiotemporal characteristics of the near-surface wind speed and wind speed percentiles with meteorological station observations in China from 1979 to 2019. Furthermore, the mechanisms of the wind speed variations are also investigated with ERA-Interim reanalysis dataset. Spatially, the wind speeds in the northern and eastern regions of China are larger than that in the central and southern regions. Seasonally, the wind speed in spring is significantly larger than that in the other seasons. The dispersion degree of wind speed in spring is larger than that in the other seasons both spatially and temporally. The near-surface wind speed in China shows significantly decreasing trends during 1979-2019, particularly in 1979-1999, but the wind speed trend reversed after 2000. After dividing the wind speed into different percentiles, it recognizes that the decreasing trend of stronger winds are more significant than that of weaker winds. The weaker the wind speed, the more significant increasing trend after 2000 . Therefore, the decreasing wind speed trend before 2000 is mainly caused by the significant reduction of strong wind, while the reversal trend after 2000 results from the increase of weak wind. The variations of the wind speed over China attributed to both the $U$ and $V$ wind components, and the variations of zonal wind is closely related to the weakened upper westerly wind field and the uneven warming between high and low latitudes.

\section{Introduction}

Near-surface wind speed changes will have important effects on many aspects of human production and life, such as surface energy balance, wind energy, pollutant dispersion and hydrological cycle, etc (AzorinMolina et al. 2014; Li et al. 2018a). The wind speed, particularly the upper percentiles of the wind speed is closely related to the wind energy, a rapidly growing alternative energy source (Pryor et al. 2006; Liu et al. 2019). The reductions in global near-surface wind speed have threatened the wind power over the past few decades (Burton et al. 2001; Tian et al. 2019; Zeng et al. 2019). Tong and Leung (2012) clarified that the wind speed was also responsible for the diffusion of 03 concentration. Lin et al. (2015) reported that wind stilling could suppress the dispersion of aerosols and amplify the impacts of aerosol emissions on solar dimming. The decreasing wind speed had also caused the reduction in potential evapotranspiration in many regions over the last several decades (Roderick et al. 2007; McVicar et al. 2012; Xie and Zhu 2013; Chu et al. 2019). Sugita et al. (2020) demonstrated that the spatial variability of turbulent fluxes was mainly caused by the wind speed differences. In addition, the near surface wind speed plays a key role in wind erosion dynamics (Zhang et al. 2019a), which could eventually result in the occurrences of desertification and sandstorm.

In the past few decades, the near-surface wind speed declined over most regions around the world (McVicar et al. 2012; Wu et al. 2018a; Tian et al. 2019), including North America (Pryor and Ledolter 2010; Wan et al. 2010), Europe (Walter et al. 2006; Najac et al. 2011; Papaioannou et al. 2011; Birsan et al. 2020), Africa (Soulouknga et al. 2018) and Asia (Bandyopadhyay et al. 2009; Fujibe 2009; Kim and Paik 2015). China is a large agricultural country, the wind speed could have important impacts on agricultural 
production through affecting the evapotranspiration (Shi et al. 2017; Sun et al. 2017). In addition, to achieve sustainable socioeconomic development as part of the global community, China had set ambitious goals for developing wind power within its national energy security framework (Liu et al. 2019). Therefore, the near-surface wind speed changes in China had also received increasing attentions. The near-surface wind speed in most areas of China had also decreased significantly over the past decades, in line with the rest of the world (Jiang et al. 2010; Guo et al. 2011; Zha et al. 2017b; Li et al. 2018b; Zheng et al. 2018; Ben et al. 2020). The main possible causes of the near-surface wind speed reductions include the decreasing trend of the spatial variance in both atmospheric pressure and air temperature (Kim and Paik 2015), the weakened East Asian trough, which has shifted eastward and northward (Jiang et al. 2010), the decreasing East Asian winter and simmer monsoons (Jiang et al. 2010), the weakening of the pressure gradient force (Wu et al. 2018b), the urbanization effect (Guo et al. 2011), the effects of land use and land cover changes (Zha et al. 2017a).

Additionally, it should be noted that the near-surface wind speed in some regions in the world have reversed in recent years (Kim and Paik 2015; Azorin-Molina et al. 2018; Blunden et al. 2018; Zeng et al. 2019). This may bring new opportunities for wind energy industry development and air pollution control. $\mathrm{Li}$ et al. (2018a) reported that the near-surface wind speed in northwest China also began to increase significantly since 1992. Therefore, it remains to be studied whether the reversal near-surface wind speed trend only appears in some regions of China or in the whole China and what caused the reversal trend.

Most of the previous studies were mainly focused on the mean near-surface wind speed trend and the possible mechanisms in wind speed changes. However, there have been few researches about different levels of wind speed and their changes. In fact, in addition to the importance of mean near-surface wind speed, extreme wind speed changes could have more significant impacts on human lives sometimes (Zhang and Wang 2020). For example, the weak wind can increase the residence time of PM2.5 and other aerosol particles (Wang et al. 2016, 2018), which poses a serious threat to air quality and human health. However, strong winds such as wind storms can blow dust (Cowie et al. 2013), damage buildings and drops. Therefore, it is also of great significance to study different levels of near-surface wind speed.

This study extends upon previous analyses and intends to analyze the spatial and temporal variations for the near-surface wind speed with observations at 679 stations in China during the last 40 years (19792019). In addition, the possible mechanisms of the wind speed variations are further analyzed. Because different levels of wind speed may have different effects on human production and life, the near-surface wind speed is divided into different percentiles during the analysis. The paper is structured as follows: Sect. 2 describes the data and methodology. The near-surface wind speed climatology, variations and possible mechanisms are presented in Sect. 3. Section 4 shows the discussion. Lastly, the summary and conclusions are shown in Sect. 5.

\section{Data And Methods \\ 2.1. Data}


The observed near-surface wind speed and wind direction data are from ground daily dataset of China (V3.0), which is provided by the China Meteorological Data Service Center (https://data.cma.cn/). The dataset contains daily mean near-surface wind speed and wind direction at 824 observation stations across China from 1951 to present. Because of the different establishment time of the observation stations and some stations with long missing measurement periods, firstly, we selected the study period that with more observation stations and coincided with the ERA-Interim period. Then, we excluded those observation stations with a continuous lack of measurement for more than 90 days. Finally, the nearsurface wind speed and wind direction data from 679 out of 824 observation stations in 1979-2019 are used in this study.

The surface air temperature, surface air pressure and the wind components at $200 \mathrm{hPa}$ and $500 \mathrm{hPa}$ that from ERA-Interim are used to analyze the mechanisms of the near-surface wind speed variations in China. ERA-Interim is an improved version of ERA-40 and is a global atmospheric reanalysis, which is available from 1st January, 1979 to 31th August, 2019. The data assimilation system used to produce ERA-Interim is based on a 2006 release of the IFS (Cy31r2). The system includes a 4-dimensional variational analysis (4D-Var) with a 12-hour analysis window. The vertical spatial resolution of the dataset is approximately $80 \mathrm{~km}$ (T255 spectral) with 60 levels from the surface up to $0.1 \mathrm{hPa}$ (https://www.ecmwf.int/en/forecasts/datasets/reanalysis-datasets/era-interim). Aside from the improved resolution over ERA-40, ERA-Interim also uses mostly the sets of observations acquired for ERA40, supplemented by data for later years from ECMWF's operational archive. In addition, ERA-Interim makes extensive use of radiances such as altimeter wave heights and radio occultation measurements (Gao et al. 2015). As the ERA-Interim datasets are not updated after August, 2019, we select the corresponding variables from 1979 to 2018 for analysis.

\subsection{Methods}

The Pearson correlation coefficients were applied to study the relationship between the surface temperature and pressure gradients and the near-surface wind speed. The t-test was used to test the significance of the correlation coefficients. The variation rates of the climatic variables were obtained through linear regression between the variables and time series. We also calculated the different wind speed percentiles (95th, 75th, 50th, 25th and 5th percentiles) at each observation station according to time series of the near-surface wind speed for every single year in 1979-2019. Over China, the 95th percentile of daily mean near-surface wind speed corresponds to the wind speed of $5 \mathrm{mžs}^{-1}$, which is as a reference to define strong wind. Consistently, the 5 th wind speed percentile is used to define weak wind (Zhang and Wang 2020). Additionally, in order to examine how the near-surface wind speed at different levels changed at the last 40 years, we also calculated the 75 th, 50th and 25th wind speed percentiles.

\section{Results}

\subsection{The climatology of the near-surface wind speed}


Figure 1 shows the spatial distributions of the annual and seasonal mean near-surface wind speed in 1979-2019. Annually, the high wind speeds mainly occur in Tibet Plateau, the northern and eastern parts of China where the mean wind speeds are basically above $2 \mathrm{mžs}^{-1}$, while the wind speeds in southwest and central China are relatively weak (Fig. 1a). Additionally, the high wind speed are also observed in coastal areas, which may be caused by the tropical cyclones and sea-land-breeze circulations (Jiang et al. 2013; Huang et al. 2016). The mean annual wind speed averaged over 679 observation stations in China is $2.2 \mathrm{mžs}^{-1}$ (Table 1). The spatial distribution patterns of the seasonal mean wind speed are similar to the annual (Fig. 1b-e). Significantly, the wind speed in spring when the mean wind speed values at most of stations are above 2 mžs $^{-1}$ (Fig. 1b) is larger than the other seasons when the wind speeds at most of the stations are below $2 \mathrm{mžs}^{-1}$ (Fig. 1c-e). The mean wind speed averaged over 679 observation stations in spring is 2.54 mžs $^{-1}$ and the smallest value appears in autumn, which is 2.03 mžs $^{-1}$ (Table 1). Therefore, the observed near-surface wind speed in China exhibits a distinct seasonal cycle.

Table 1

The annual mean near-surface wind speeds (unit: mžs ${ }^{-1}$ ) averaged over 679 observation stations in China from 1979 to 2019.

\begin{tabular}{|llllll|}
\hline & ANN & MAM & JJA & SON & DJF \\
\hline Mean & 2.20 & 2.54 & 2.11 & 2.03 & 2.11 \\
\hline
\end{tabular}

Figure 2 is the box plot of the annual and seasonal mean near-surface wind speed for 679 observation stations. Consistent with Fig. 1 and Table 1, it can be seen that the maximum wind speed, minimum wind speed, median wind speed, mean wind speed, 75th and 25th wind speed percentiles in spring are all larger than the annual and the other seasonal results. Moreover, Fig. 2 also shows the interquartile range (25th and 75th percentiles) of the near-surface wind speed. As shown, the wind speed in spring exhibits the highest interquartile range, denoting the highest spatial dispersion in spring. The wind speed in winter and autumn show moderate interquartile ranges and summer presents the lowest.

In order to study the dispersion degrees of the near-surface wind speed time series at each observation station, we also calculated the standard deviations of the near-surface wind speed (Fig. 3). The standard deviations show similar spatial patterns with that of the wind speed both annually and seasonally. That is to say the regions with larger wind speed correspond to the regions with larger standard deviations. The dispersion degrees of the near-surface wind speed in spring and winter are higher than that in summer and autumn. This may be correlated with Siberian high and North Pacific index, which were the factors influencing surface wind speed decadal variabilities (Zhang and Wang 2020).

\subsection{Trends of the near-surface wind speed}

The spatial distribution of the linear trend for the annual mean near-surface wind speed is shown in Fig. 4. It can be seen that the wind speed in most areas of China decreased in 1979-2019. In more detail, 
more than 447 out of 679 observation stations have decreased wind speed while only 232 stations show increased trend. The observation stations with increased wind speed mainly distributed in Northwest China except Qinghai province, Southwest China except Tibet Autonomous region and South China. Zheng et al. (2018) suggested that the increased wind speed is correlated with the enhancement of the Asian Meridional Circulation (AMC). The mean wind speed averaged over all 679 observation stations in China decreased at a rate of -0.07 mžs $^{-1} \check{z}(10 a)^{-1}$, which passed the $95 \%$ significance test, in 19792019 (Fig. 5). Zeng et al. (2019) showed that the near-surface wind speed in Southeast Asian has increased since 2000. Therefore, in order to investigate whether the wind speed in China has also risen since 2000, we divided the study period into two segments, one of which is from 1979 to 1999 and the other is from 2000 to 2019. It can be seen from Fig. 5 that the mean wind speed before 2000 present significantly decreased trend at a rate of -0.17 mžs $^{-1} \check{z}(10 a)^{-1}$, which is obviously larger than that in 1979-2019. After 2000, the mean wind speed in China also presents increasing trend, although the trend does not pass the $95 \%$ significance test.

Spatially, the wind speed at 502 out of 679 of the observation stations presents decreased trend in 19791999 (Table 2) and the changing rates at most stations are more than $-0.2 \mathrm{mžs}^{-1} \mathrm{z}(10 a)^{-1}$ (Fig. 6a). In addition, the wind speed at most stations such as in Xinjiang, Tibetan Plateau and Northeast China, etc. decreased with even larger rates, which finally results in the more significant decreased wind speed trend averaged over 679 stations in 1979-1999 than that in 1979-2019. However, the wind speed in 20002019 show increased trend at more than half of the observation stations (Table 2) and the increasing rates at most stations are above $0.1 \mathrm{mžs}^{-1} \mathrm{z}(10 \mathrm{a})^{-1}$ (Fig. 6b). Finally, the mean wind speed averaged over 679 stations shows a reversal trend after 2000 (Fig. 5). Zhang et al. (2019b) also showed the insignificantly decreasing wind speed trend from 2000 to 2015. Our results further suggest that the nearsurface wind speed in China increased from 2000 to 2019.

Table 2

The number of stations with decreased and increased near-surface wind speed among 679 observation stations in 1979-1999 and 2000-2019.

\begin{tabular}{|clcccccc|}
\hline & & Mean & $\mathbf{9 5 \%}$ & $\mathbf{7 5 \%}$ & $\mathbf{5 0 \%}$ & $\mathbf{2 5 \%}$ & $\mathbf{5 \%}$ \\
\hline $1979-1999$ & Increased & 177 & 102 & 153 & 205 & 260 & 302 \\
\cline { 2 - 8 } & Decreased & 502 & 577 & 526 & 474 & 419 & 377 \\
$2000-2019$ & Increased & 371 & 260 & 316 & 386 & 448 & 531 \\
\cline { 2 - 7 } & Decreased & 308 & 419 & 363 & 293 & 231 & 148 \\
\hline
\end{tabular}

Figure 1a and Fig. 4 also present that the regions with more significant wind speed trend correspond to the regions with larger wind speed. Therefore, the wind speed is divided into different percentiles including 95th percentile, 75th percentile, 50th percentile, 25th percentile and 5th percentile to study the variations of wind speed in different levels. Figure 7 presents the variations of the annual wind speed and different wind speed percentiles averaged over 679 stations in 1979-2019, 1979-1999 and 2000-2019. 
It can be seen that the larger wind speed the more significant wind speed reduction trend is from 1979 to 2019. The change rate of the 95th wind speed percentile even reaches to $-0.31 \mathrm{mžs}{ }^{-1} \check{z}(10 a)^{-1}$ and passes the $95 \%$ significance test (Fig. 7a). The change rates of the 75 th $\left(-0.14\right.$ mžs $\left.^{-1} \check{z}(10 a)^{-1}\right)$ and 50 th $\left(-0.06\right.$ mžs $\left.^{-1} \check{z}(10 a)^{-1}\right)$ wind speed percentile also pass the $95 \%$ significance test, although the decreasing trends are not as significant as the 95th wind speed percentile (Fig. 7b and 7c). It should be noted that the 25th and 5th wind speed percentiles show increasing trend in 1979-2019 with the former fails to pass the $95 \%$ significance test and the later does (Fig. $7 \mathrm{~d}$ and $7 \mathrm{e}$ ). Through analyzing the variations of the wind speed percentiles before and after 2000, it is found that no matter the high or the low wind speed percentile show significant decreasing trends in 1979-1999, and the trends are even more significant than that in 1979-2019. Similarly, the reduction rates of higher wind speed percentiles are also larger than that of lower wind speed percentiles in 1979-1999. After 2000, the 95th and 75th wind speed percentiles are still decreasing insignificantly. However, the 50th, 25th and 5th wind speed percentiles show increased trends and the lower the wind speed percentile is, the more significant the reversal trend is. The 5th wind speed percentile even has an increase rate that is close to 0.19 mžs ${ }^{-}$ $1 \check{z}(10 a)^{-1}$, which passes the $95 \%$ significance test (Fig. 7e).

The spatial distributions of the linear trend for the different wind speed percentiles in 1979-1999 are shown in Fig. 8. The 95th wind speed percentile at about $85 \%$ of the observation stations (Table 2 ) show significant decreasing trend and the change rates at most of the stations are above -6 mžs $^{-1} \check{z}(10 a)^{-1}$ (Fig. 8a). The number of stations with decreased wind speed trend reduced gradually along with the wind speed percentiles go down, and the amplitude of the wind speed reduction also decreased gradually. The spatial distribution patterns of the trends for the 75th (Fig. 8b) and 50th (Fig. 8c) wind speed percentiles are similar to that of the annual mean wind speed (Fig. 6a). For the 25th and 5th wind speed percentiles, the number of stations with decreased wind speed trend reduced more significantly (Table 2 ) and the decreasing rates are basically below $-0.2 \mathrm{mžs}^{-1} \check{z}(10 \mathrm{a})^{-1}$, especially for the 5 th percentile wind speed (Fig. 8e). The change rates are positive at 302 out 679 observation stations for the 5 th wind speed percentile as shown in Table 2. This ultimately leads to the decreased trend of the weak wind speed is not so significant compared with that of the stronger wind speed in 1979-1999 (Fig. 7).

The 95th and 75th wind speed percentiles at most observation stations still present decreased trend especially for the 95th wind speed percentile in 2000-2019 (Fig. 9a and b), even though the number of stations with decreasing trend is less than that in 1979-1999, which finally bring about the mean 95th and 75th wind speed percentiles averaged over 679 stations still decreased from 2000 to 2019 (Fig. 7a and b). Different from the 95th and 75th wind speed percentiles, the 50th wind speed percentile at most of stations show increased trend in 2000-2019 (Fig. 9c), which results in the reversal trend for the mean 50th wind speed percentile averaged over 679 stations (Fig. 7c). Figure $9 \mathrm{~d}$ and $9 \mathrm{e}$ show that the 25th and 5th wind speed percentiles at the vast majority of the observation stations in China have increasing trend in 2000-2019 and the change rates at most of the stations exceed $0.3 \mathrm{mžs}^{-1} \check{z}(10 a)^{-1}$. Among 679 observation stations, 448 and 531 out of 679 stations show increasing trend for the 25th and 5 th wind speed percentiles, respectively (Table 2). 
To sum up, the mean wind speed in China decreased significantly from 1979 to 2019, and the decreasing trend is more significant in 1979-1999. After 2000, the mean wind speed has reversal trend even though the trend fails to pass the $95 \%$ significance test. In addition, the strong wind reduced more quickly than the weak wind in the whole study period and especially before 2000. It's worth to be noted that the smaller the wind speed is, the more significant reversal trend after 2000. Therefore, the significant decreasing trend of the mean wind speed is mainly caused by the decreased strong wind, but the reversal trend of the mean wind speed after 2000 mainly due to the increase trend of weak wind. Zhang and Wang (2020) also showed that the decreasing trend for the wind speed was primarily caused by strong wind. As for the more significant decreasing trend for strong wind than for weak wind, it maybe correlated with the surface roughness increases. Some studies showed that the surface roughness had a stronger influence on strong winds than weak winds (Li et al. 2011; Zhang and Wang 2020).

\subsection{The mechanism of the near-surface wind speed variations}

The variations of the near-surface wind speed may be attributed to the changes of the upper wind fields and the uneven warming between high and low latitude zones. Therefore, the reasons for the near-surface wind speed variations in China from the following two aspects are analyzed.

\subsubsection{The variation of the upper wind fields}

Figure 10 shows the spatial distribution of the linear trends for the absolute near-surface $U$ and $V$ wind components in 1979-1999 and 2000-2019. Because wind speed is the root mean square of the sum of the squares for the $U$ and $V$ wind components, so the variations of the absolute value for the $U$ and $V$ wind components are analyzed. The absolute $U$ wind component presents decreased trend in 1979-1999 at majority of the observation stations (419 out of 679 stations), and the change rates at most stations reach to -0.1 mžs $^{-1}$ or more (Fig. 10a). In addition, the spatial distribution characteristic of the trend for the absolute $U$ wind component is in good agreement with that of the wind speed as shown in Fig. 6a in 1979-1999. Thus, the significant decreased trend of the near-surface wind speed in 1979-1999 is closely related to the weakened near-surface zonal wind. It's worth noting that the spatial distribution of the trend for the absolute $\mathrm{V}$ wind component (Fig. 10b) is also similar to that of the $\mathrm{U}$ wind component in 1979-1999. Therefore, the decrease of near-surface wind speed from 1979 to 1999 is co-determined by the changes of both the $U$ and $V$ components. After 2000 , both the $U$ and $V$ wind components present increasing trend at most stations (360 out of 679 stations for the $U$ wind component and 360 out of 679 stations for the $V$ wind component) and the spatial distribution patterns of their linear trends (Fig. 10c and 10d) are also similar to that of the near-surface wind speed (Fig. 6b), which shows that the reversal trend for the near-surface wind speed after 2000 is also jointly determined by the changes of the $U$ and $V$ wind components.

Further, the variations of the near-surface wind components may be affected by the changes of upper wind field through momentum down transmission. Figure 11 shows the linear trends of the zonal winds 
at $500 \mathrm{hPa}$ and $200 \mathrm{hPa}$ in $1979-1999$ and $2000-2018$. The annual mean zonal wind at $200 \mathrm{hPa}$ weakened in 1979-1999 over most regions above China and the weakened center is above the northern regions of China, where the weakening rate reaches to -3 mžs $^{-1} \check{z}(10 a)^{-1}$ and more (Fig. 11a). The zonal wind at $500 \mathrm{hPa}$ also presents weakened trend at most areas above China in 1979-1999 (Fig. 11c), even though the weakening trend is not as significant as that at $200 \mathrm{hPa}$, especially above northern regions of China. Ultimately, we speculate that the significant decrease of the near-surface $U$ wind component in China from 1979 to 1999 may be related to the weakened westerly wind at upper levels based on the momentum downward transfer principle. Figure $11 \mathrm{~b}$ shows that the zonal wind at $200 \mathrm{hPa}$ after 2000 present insignificant increasing trend. Similarly, the zonal wind at $500 \mathrm{hPa}$ also increased in 2000-2018 and the increase amplitude is also less than that at $200 \mathrm{hPa}$ (Fig. 11d). Therefore, the reversal trend of the annual mean near-surface wind speed after 2000 is also closely related to the strengthening of upper westerly winds.

In summary, the variations of the near-surface wind speed are caused by the changes for both the nearsurface $\mathrm{U}$ and $\mathrm{V}$ wind components, and the variations of the near-surface $\mathrm{U}$ wind component is closely related to the changes of the upper wind fields. Zhang et al. (2019b) showed that the variations of $v$ wind component are closely associated to the weakened Siberian High (SH).

\subsubsection{The uneven warming between high and low latitude zones}

Horizontal surface pressure gradient force is the main driving for the horizontal air motion. However, the changes of the surface pressure gradient is driven by the changes of the horizontal temperature gradient (Li et al. 2018a). So, the analysis for the changes to the near-surface air temperature and pressure gradient and their effects on near-surface wind speed variability are of great significance.

Figure 12 shows the spatial distributions of the linear trends for the surface air temperature and pressure, and Fig. 13 shows the temporal variabilities of anomalies for the surface air temperature and surface pressure gradient between high $\left(50^{\circ} \mathrm{N}-60^{\circ} \mathrm{N}, 75^{\circ} \mathrm{E}-120^{\circ} \mathrm{E}\right)$ and middle $\left(35^{\circ} \mathrm{N}-45^{\circ} \mathrm{N}, 75^{\circ} \mathrm{E}-120^{\circ} \mathrm{E}\right)$ latitude zone, and that between low $\left(20^{\circ} \mathrm{N}-30^{\circ} \mathrm{N}, 75^{\circ} \mathrm{E}-120^{\circ} \mathrm{E}\right)$ and the middle latitude zone in $1979-1999$ and 2000-2019. The annual surface air temperature shows significant warming trend at most regions except for the western parts of China in 1979-1999 (Fig. 12a). It's worth noting that the warming trend in the high latitude zone is more significant than that in the middle latitude zone, where the warming trend is also more significant than that in low latitude zone. Generally speaking, the annual mean surface air temperature at higher latitude is lower than that at lower latitude. However, because the warming rates in higher latitude zone is significantly larger than that in lower latitude zone, the surface temperature gradient between higher latitude and lower latitude zones become smaller and smaller with time in 19791999 (Fig. 13a). The surface pressure at most areas in the high latitude zone presents decreasing trend, but that in middle and low latitude zones show increasing trend, and the increasing trend in low latitude zone is less significant than that in middle latitude zone (Fig. 12c), which finally resulting the negative trend in the surface pressure gradient (Fig. 13c). The interannual variations in mean near-surface wind 
speed and wind speed percentiles all significantly correlated with the air temperature gradient in different latitude zones (Table 3). Therefore, the decreasing surface air temperature gradient leads to the reduction of the horizontal pressure gradient force, which eventually causes the significantly decreasing trend of the near-surface wind speed in 1979-1999. Zhang et al. (2021) clarified that the declining near-surface wind speed in northern China is likely attributed to the uneven warming. Ge et al. (2021) also suggests that the spatially inhomogeneous variations in surface air temperature in Eurasia's mid-high latitudes may be the main reason for the near-surface wind speed variations in Northwest China. Our study shows the similar results to theirs. In addition, the significant correlation between the wind speed and the air temperature gradient between middle and low latitudes zones indicates that the declined wind speed in the southern regions of China is also correlated to the uneven warming in 1979-1999.

Table 3

The time correlation coefficients between the surface temperature and pressure gradients and the mean near-surface wind speed and wind speed percentiles in 1979-1999 and 2000-2019. The bold fonts indicate that the correlation coefficients that have passed significance test at the $90 \%$ confidence level.

\begin{tabular}{|c|c|c|c|c|c|c|c|c|}
\hline & & & Mean & $95 \%$ & $75 \%$ & $50 \%$ & $25 \%$ & $5 \%$ \\
\hline \multirow{4}{*}{$\begin{array}{l}\left(50^{\circ} \mathrm{N} \sim 60^{\circ} \mathrm{N}\right)-\left(35^{\circ} \mathrm{N} \sim\right. \\
\left.45^{\circ} \mathrm{N}\right)\end{array}$} & \multirow{2}{*}{$\begin{array}{l}1979- \\
1999\end{array}$} & $\mathrm{TG}$ & 0.43 & 0.42 & 0.44 & 0.40 & 0.42 & 0.39 \\
\hline & & $P G$ & 0.24 & 0.17 & 0.24 & 0.25 & 0.34 & 0.33 \\
\hline & \multirow{2}{*}{$\begin{array}{l}1999- \\
2018\end{array}$} & $\mathrm{TG}$ & 0.22 & 0.13 & 0.16 & 0.14 & 0.07 & 0.07 \\
\hline & & $P G$ & -0.06 & -0.21 & -0.13 & -0.03 & 0.13 & 0.16 \\
\hline \multirow{4}{*}{$\begin{array}{l}\left(35^{\circ} \mathrm{N} \sim 45^{\circ} \mathrm{N}\right)-\left(20^{\circ} \mathrm{N} \sim\right. \\
\left.30^{\circ} \mathrm{N}\right)\end{array}$} & \multirow{2}{*}{$\begin{array}{l}1979- \\
1999\end{array}$} & TG & 0.40 & 0.33 & 0.40 & 0.41 & 0.47 & 0.48 \\
\hline & & $P G$ & 0.21 & 0.21 & 0.20 & 0.17 & 0.20 & 0.12 \\
\hline & \multirow{2}{*}{$\begin{array}{l}1999- \\
2018\end{array}$} & TG & -0.17 & -0.37 & -0.32 & -0.18 & 0.18 & 0.29 \\
\hline & & $P G$ & -0.02 & 0.03 & 0.01 & 0.00 & -0.05 & -0.05 \\
\hline
\end{tabular}

The surface air temperature continues to rise in most areas since 2000 (Fig. 12b). However, the warming rates in the lower latitude zones are larger than that in the higher latitude zones, which is different from that in 1979-1999. This makes temperature gradient between the higher and lower latitude zones increase gradually (Fig. 13b). The interannual variation trend in annual wind speed is consistent with the trend of the temperature gradient after 2000. The surface pressure in 2000-2018 presents increased trend at most areas except for Xinjiang, Southwest and Northeast China (Fig. 12d). Similar to the temperature gradient, both the pressure gradients between the high and middle latitude zone, and that between the low and middle latitude zone present insignificantly increased trend (Fig. 13d). Table 3 shows that neither temperature nor pressure gradient is significantly correlated to the interannual wind speed and wind speed percentiles, particularly between the low and middle latitude zones. Therefore, the variations of the wind speed in 2000-2019 may be also influenced by other factors besides the uneven warming. Zhang and Wang (2020) indicated that atmospheric circulation was not the key cause of nearsurface wind speed stilling but was the main cause of near-surface wind speed recovery over China since 
the early twenty-first century. Deng et al. (2021b) showed that the recent reversal of the wind speed trend is most likely a multi-decadal fluctuation related to the Pacific and Atlantic climate variations. In addition, research had also shown that the decadal strengthening of the East Asian winter monsoon (EAWM) may have resulted in an upward trend of the near-surface wind speed in Northwest China after the early 2000s by strengthening the Siberian High (SH).

\section{Discussions}

We investigated the trend and change mechanisms for the near-surface wind speed during 1979-2019 using the observations at 679 stations in China. What is noteworthy is that observation stations are of scarcity and uneven distributed in the vast northwest regions of China, especially in Xinjiang and the Qinghai-Tibet Plateau, where most of the observations located in the valleys that with lower altitude and easily accessible to humans. These make our research have certain insufficiency on the near-surface wind speed based only on the station observations. Studying near-surface wind speed with high coverage dataset is crucial to understand the wind speed comprehensively. At present, the commonly used grid datasets mainly include reanalysis and climate model simulations. However, many studies have shown that the reanalysis and model simulations had larger error in simulating the trend of near-surface wind speed compared to the observations and the results were largely diverse among themselves ( $\mathrm{Li}$ et al. 2017; Torralba et al. 2017; Yu et al. 2019; Miao et al. 2020; Wu et al. 2020). Therefore, it is necessary to make a further analysis of the near-surface wind speed characteristics in China with high resolution grid data that with better performance in descripting the trend. The near-surface wind speed and its variation characteristics are analyzed on annual and monthly time scales in this study. In the future, it is very necessary to research the wind speed on daily, hourly and even smaller time scale to catch more wind speed variation information.

In this paper, the wind speed change mechanisms in China are analyzed from two aspects: upper wind fields and uneven warming between high and low latitude zones. In addition to the above two aspects, the variation of near-surface wind speed may be closely related to the aerosol forcing and land use changes (Deng et al. 2021a), urbanization (Wang et al. 2020), larger-scale ocean-atmosphere circulations (Zha et al. 2021), Arctic Oscillation (AO) (Ge et al. 2021), etc. In the future, it would be of great significance to study the variation mechanisms of near-surface wind speed in China from various aspects, and to quantitatively identify the main influencing factors of near-surface wind speed variations in different periods and regions.

\section{Summary And Conclusions}

The wind speed is the key for the wind power industry developing. Changes for the near-surface wind speed could have some profound influences on environment and socioeconomic. Therefore, the study of the near-surface wind speed and its variations is of great significance. In this study, the spatial and temporal characteristics and variation mechanisms of the near-surface wind speed in 1979-2019 are 
analyzed using the observations at 679 observation stations in China and ERA-Interim datasets. The followings are obtained:

1) The annual mean wind speeds in northern and eastern parts of China, Tibetan Plateau and the coastal zone are larger than that in the other regions of China. The wind speed at most stations in those regions

are above $2 \mathrm{mžs}^{-1}$. Seasonally, the wind speed in spring is significantly larger than the other seasons and the mean wind speed averaged over 679 stations reaches to $2.54 \mathrm{mžs}^{-1}$. In addition, the dispersion degree of the wind speed in spring is larger than that in the other seasons both spatially and temporally.

2) The wind speed in China shows significantly decreasing trends at 447 out 679 of observation stations during 1979 and 2019. The stations with significantly stilling wind speed trend mainly concentrates in Northeast China, North China, East China, Central China, Tibetan Plateau and the southeastern coastal areas of China, where the wind speed is commonly larger than in the other regions. In 1979-1999, the decreasing trend of the wind speed is particularly significant and the change rate of the annual mean wind speed reaches to -0.16 mžs $^{-1} \check{z}(10 a)^{-1}$. Consistent with other studies, the wind speed in China also shows reversal trend after 2000. This could create new opportunities for the development of the wind energy industry in China.

3) The regions with larger wind speed generally correspond to the regions with significantly decreasing wind speed. After dividing the wind speed into different percentiles, we find that the decreasing trend of the high wind speed percentiles (95th and 75th percentile) are more significant than that of the low wind speed percentiles, especially in 1979-1999. The change rate of the 95th wind speed percentile in 19791999 even reaches to -0.43 mžs $^{-1} \check{z}(10 a)^{-1}$ and passes the $95 \%$ significance test. The lower percentile wind speed, the more significant reversal trend since 2000 . Therefore, the rapid mean wind speed decrease is mainly caused by the significant reduction of strong wind, while the reversal trend of the mean wind speed since 2000 mainly results from the variation of weak wind.

4) The variations of the near-surface wind speed in China during 1979 and 2019 are caused by the changes of both the near-surface $U$ and $V$ components. On the one hand, the variations of the nearsurface zonal wind are mainly due to the weakening of the upper westerlies, which finally results the variations of the near-surface wind speed through the momentum down transmission. On the other hand, the unevenness of warming between high and low latitude, which results the changes in pressure gradient forces is one of the important reasons for the variation of near surface wind speed.

\section{Declarations}

Funding This work is jointly supported by the Strategic Priority Research Program of Chinese Academy of Sciences (XDA2006010202) and the Second Tibetan Plateau Scientific Expedition and Research (STEP) program (2019QZKK010314).

Conflicts of interest The authors declare that they have no conflict of interest. 
Data Availability Wind speed data from station observations can be accessed at China Meteorological Administration (https://data.cma.cn/), ERA-Interim Reanalysis were downloaded from ECMWF (https://www.ecmwf.int/en/forecasts/datasets/reanalysis-datasets/era-interim).

Code availability Code is available on request $\square$

Authors contributions Xia Li analyzed the data and wrote the manuscript. Yongjie Pan provided guidance and revised the manuscript. Yingsha Jiang revised the manuscript and improved grammar.

Ethics approval The authors confirm that this article is an original research.

Consent to participate The authors confirm that this article has not been published previously in any journal.

Consent for publication The authors have agreed to submit this manuscript in its current form for publication in the journal.

\section{Acknowledgements}

We wish to acknowledge the Editor and the anonymous reviewers for their detailed and helpful comments to the original manuscript. We also acknowledge China Meteorological Administration and European Centre for Medium-Range Weather Forecasts for providing the datasets.

\section{References}

1. Azorin-Molina C, Rehman S, Guijarro JA, et al (2018) Recent trends in wind speed across Saudi Arabia, 1978-2013: a break in the stilling. Int J Climatol. https://doi.org/10.1002/joc.5423

2. Azorin-Molina C, Vicente-Serrano SM, Mcvicar TR, et al (2014) Homogenization and assessment of observed near-surface wind speed trends over Spain and Portugal, 1961-2011. J Clim. https://doi.org/10.1175/JCLI-D-13-00652.1

3. Bandyopadhyay A, Bhadra A, Raghuwanshi NS, Singh R (2009) Temporal trends in estimates of reference evapotranspiration over India. J Hydrol Eng. https://doi.org/10.1061/(ASCE)HE.19435584.0000006

4. Ben Y, Mei Y, Chen Y, et al (2020) Inter- and intra-annual wind speed variabilities in wide valley regions of the middle reaches of the Yarlung Tsangpo River, China. Sci Rep. https://doi.org/10.1038/s41598020-69392-2

5. Birsan MV, Nita IA, Craciun A, et al (2020) Observed changes in mean and maximum monthly wind speed over Romania since ad 1961. Rom Reports Phys

6. Blunden J, Hartfield G, Arndt DS (2018) State of the climate in 2017. Bull Am Meteorol Soc. https:// doi.org/10.1175/2018BAMSSTATEOFTHECLIMATE.1

7. Burton T, Sharpe D, Jenkind N, Bossanyi E (2001) Wind Energy Handbook 
8. Chu R, Li M, Islam ARMT, et al (2019) Attribution analysis of actual and potential evapotranspiration changes based on the complementary relationship theory in the Huai River basin of eastern China. Int J Climatol. https://doi.org/10.1002/joc.6060

9. Cowie SM, Knippertz P, Marsham JH (2013) Are vegetation-related roughness changes the cause of the recent decrease in dust emission from the Sahel? Geophys Res Lett 40:1868-1872. https://doi.org/10.1002/grl.50273

10. Deng K, Azorin-molina C, Minola L, Chen D (2021a) Global Near-Surface Wind Speed Trends in Observation and CMIP6 Historical Simulation for 1850 - 2014. 5194

11. Deng K, Azorin-molina C, Yang S, Zhang G (2021b) Terrestrial stilling will continue during the 21 st century. Res Sq 1-14

12. Fujibe F (2009) Relation between Long-term Temperature and Wind Speed Trends at Surface Observation Stations in Japan. Sci Online Lett Atmos. https://doi.org/10.2151/sola.2009-021

13. Ge J, Feng D, You Q, et al (2021) Characteristics and causes of surface wind speed variations in Northwest China from 1979 to 2019. Atmos Res 254:105527. https://doi.org/10.1016/j.atmosres.2021.105527

14. Guo H, Xu M, Hu Q (2011) Changes in near-surface wind speed in China: 1969-2005. Int J Climatol. https://doi.org/10.1002/joc.2091

15. Huang M, Gao Z, Miao S, Xu X (2016) Characteristics of sea breezes over the Jiangsu coastal area, China. Int J Climatol 36:3908-3916. https://doi.org/10.1002/joc.4602

16. Jiang Y, Luo Y, Zhao Z (2013) Maximum wind speed changes over China. Acta Meteorol Sin 27:6374. https://doi.org/10.1007/s13351-013-0107-x

17. Jiang Y, Luo Y, Zhao Z, Tao S (2010) Changes in wind speed over China during 1956-2004. Theor Appl Climatol. https://doi.org/10.1007/s00704-009-0152-7

18. Kim JC, Paik K (2015) Recent recovery of surface wind speed after decadal decrease: a focus on South Korea. Clim Dyn. https://doi.org/10.1007/s00382-015-2546-9

19. Li X, Gao Y, Pan Y, Xu Y (2017) Evaluation of near-surface wind speed simulations over the Tibetan Plateau from three dynamical downscalings based on WRF model. Theor. Appl. Climatol. 1-13

20. Li Y, Chen Y, Li Z, Fang G (2018a) Recent recovery of surface wind speed in northwest China. Int J Climatol. https://doi.org/10.1002/joc.5679

21. Li Z, Song L, Ma H, et al (2018b) Observed surface wind speed declining induced by urbanization in East China. Clim Dyn. https://doi.org/10.1007/s00382-017-3637-6

22. Li Z, Yan Z, Tu K, et al (2011) Changes in wind speed and extremes in Beijing during 1960-2008 based on homogenized observations. Adv Atmos Sci. https://doi.org/10.1007/s00376-010-0018-z

23. Lin C, Yang K, Huang J, et al (2015) Impacts of wind stilling on solar radiation variability in China. Sci Rep 5:. https://doi.org/10.1038/srep15135

24. Liu F, Sun F, Liu W, et al (2019) On wind speed pattern and energy potential in China. Appl Energy. https://doi.org/10.1016/j.apenergy.2018.12.056 
25. McVicar TR, Roderick ML, Donohue RJ, et al (2012) Global review and synthesis of trends in observed terrestrial near-surface wind speeds: Implications for evaporation. J. Hydrol.

26. Miao H, Dong D, Huang G, et al (2020) Evaluation of Northern Hemisphere surface wind speed and wind power density in multiple reanalysis datasets. Energy 200:117382. https://doi.org/10.1016/j.energy.2020.117382

27. Najac J, Lac C, Terray L (2011) Impact of climate change on surface winds in France using a statistical-dynamical downscaling method with mesoscale modelling. Int J Climatol. https://doi.org/10.1002/joc.2075

28. Papaioannou G, Kitsara G, Athanasatos S (2011) Impact of global dimming and brightening on reference evapotranspiration in Greece. J Geophys Res Atmos.

https://doi.org/10.1029/2010JD015525

29. Pryor SC, Ledolter J (2010) Addendum to "Wind speed trends over the contiguous United States." J Geophys Res. https://doi.org/10.1029/2009jd013281

30. Pryor SC, Schoof JT, Barthelmie RJ (2006) Winds of change?: Projections of near-surface winds under climate change scenarios. Geophys Res Lett. https://doi.org/10.1029/2006GL026000

31. Roderick ML, Rotstayn LD, Farquhar GD, Hobbins MT (2007) On the attribution of changing pan evaporation. Geophys Res Lett 34:. https://doi.org/10.1029/2007GL031166

32. Shi Z, Xu L, Yang X, et al (2017) Trends in reference evapotranspiration and its attribution over the past 50 years in the Loess Plateau, China: implications for ecological projects and agricultural production. Stoch Environ Res Risk Assess. https://doi.org/10.1007/s00477-015-1203-5

33. Soulouknga MH, Doka SY, N.Revanna, et al (2018) Analysis of wind speed data and wind energy potential in Faya-Largeau, Chad, using Weibull distribution. Renew Energy. https://doi.org/10.1016/j.renene.2018.01.002

34. Sugita M, Ogawa S, Kawade M (2020) Wind as a Main Driver of Spatial Variability of Surface Energy Balance Over a Shallow 102-km2 Scale Lake: Lake Kasumigaura, Japan. Water Resour Res. https://doi.org/10.1029/2020WR027173

35. Sun S, Zhang CF, Li X, et al (2017) Sensitivity of crop water productivity to the variation of agricultural and climatic factors: A study of Hetao irrigation district, China. J Clean Prod. https://doi.org/10.1016/j.jclepro.2016.11.020

36. Tian Q, Huang G, Hu K, Niyogi D (2019) Observed and global climate model based changes in wind power potential over the Northern Hemisphere during 1979-2016. Energy. https://doi.org/10.1016/j.energy.2018.11.027

37. Tong NYO, Leung DYC (2012) Effects of building aspect ratio, diurnal heating scenario, and wind speed on reactive pollutant dispersion in urban street canyons. J Environ Sci (China). https://doi.org/10.1016/S1001-0742(11)60971-6

38. Torralba V, Doblas-Reyes FJ, Gonzalez-Reviriego N (2017) Uncertainty in recent near-surface wind speed trends: A global reanalysis intercomparison. Environ Res Lett 12: https://doi.org/10.1088/1748-9326/aa8a58 
39. Walter A, Keuler K, Jacob D, et al (2006) A high resolution reference data set of German wind velocity 1951-2001 and comparison with regional climate model results. Meteorol Zeitschrift.

https://doi.org/10.1127/0941-2948/2006/0162

40. Wan H, Wang XL, Swail VR (2010) Homogenization and trend analysis of Canadian near-surface wind speeds. J Clim. https://doi.org/10.1175/2009JCLI3200.1

41. Wang J, Feng J, Yan Z, Zha J (2020) Urbanization Impact on Regional Wind Stilling: A Modeling Study in the Beijing-Tianjin-Hebei Region of China. J Geophys Res Atmos 125:1-17. https://doi.org/10.1029/2020JD033132

42. Wang X, Dickinson RRE, Su L, et al (2018) PM2.5 pollution in China and how it has been exacerbated by terrain and meteorological conditions. Bull Am Meteorol Soc 99:105-120. https://doi.org/10.1175/BAMS-D-16-0301.1

43. Wang X, Wang K, Su L (2016) Contribution of Atmospheric Diffusion Conditions to the Recent Improvement in Air Quality in China. Sci Rep 6:1-11. https://doi.org/10.1038/srep36404

44. Wu J, Shi Y, Xu Y (2020) Evaluation and Projection of Surface Wind Speed Over China Based on CMIP6 GCMs. J Geophys Res Atmos 125:. https:// doi.org/10.1029/2020JD033611

45. Wu J, Zha J, Zhao D, Yang Q (2018a) Changes in terrestrial near-surface wind speed and their possible causes: an overview. Clim Dyn. https://doi.org/10.1007/s00382-017-3997-y

46. Wu J, Zha J, Zhao D, Yang Q (2018b) Changes of wind speed at different heights over eastern China during 1980-2011. Int J Climatol. https://doi.org/10.1002/joc.5681

47. Xie H, Zhu X (2013) Reference evapotranspiration trends and their sensitivity to climatic change on the Tibetan Plateau (1970-2009). Hydrol Process 27:3685-3693. https://doi.org/10.1002/hyp.9487

48. Yu J, Zhou T, Jiang Z, Zou L (2019) Evaluation of near-surfacewind speed changes during 1979 to 2011 over china based on five reanalysis datasets. Atmosphere (Basel) 10:. https://doi.org/10.3390/ATMOS10120804

49. Zeng Z, Ziegler AD, Searchinger T, et al (2019) A reversal in global terrestrial stilling and its implications for wind energy production. Nat Clim Chang. https://doi.org/10.1038/s41558-019-06226

50. Zha J, Shen C, Zhao D, et al (2021) Slowdown and reversal of terrestrial near-surface wind speed and its future changes over eastern China. Environ Res Lett 16:. https://doi.org/10.1088/17489326/abe2cd

51. Zha J, Wu J, Zhao D (2017a) Effects of land use and cover change on the near-surface wind speed over China in the last 30 years. Prog Phys Geogr. https://doi.org/10.1177/0309133316663097

52. Zha J, Wu J, Zhao D, Yang Q (2017b) Changes of the probabilities in different ranges of near-surface wind speed in China during the period for 1970-2011. J Wind Eng Ind Aerodyn.

https://doi.org/10.1016/j.jweia.2017.07.019

53. Zhang G, Azorin-Molina C, Chen D, et al (2021) Uneven Warming Likely Contributed to Declining NearSurface Wind Speeds in Northern China Between 1961 and 2016. J Geophys Res Atmos 126:1-24. https://doi.org/10.1029/2020JD033637 
54. Zhang G, Azorin-Molina C, Shi P, et al (2019a) Impact of near-surface wind speed variability on wind erosion in the eastern agro-pastoral transitional zone of Northern China, 1982-2016. Agric For Meteorol. https://doi.org/10.1016/j.agrformet.2019.02.039

55. Zhang R, Zhang S, Luo J, et al (2019b) Analysis of near-surface wind speed change in China during 1958-2015. Theor Appl Climatol 137:2785-2801. https://doi.org/10.1007/s00704-019-02769-0

56. Zhang Z, Wang K (2020) Stilling and recovery of the surface wind speed based on observation, reanalysis, and geostrophic wind theory over China from 1960 to 2017. J Clim. https://doi.org/10.1175/JCLI-D-19-0281.1

57. Zheng J, Li B, Chen Y, et al (2018) Spatiotemporal variation of upper-air and surface wind speed and its influencing factors in northwestern China during 1980-2012. Theor Appl Climatol. https://doi.org/10.1007/s00704-017-2346-8

\section{Figures}



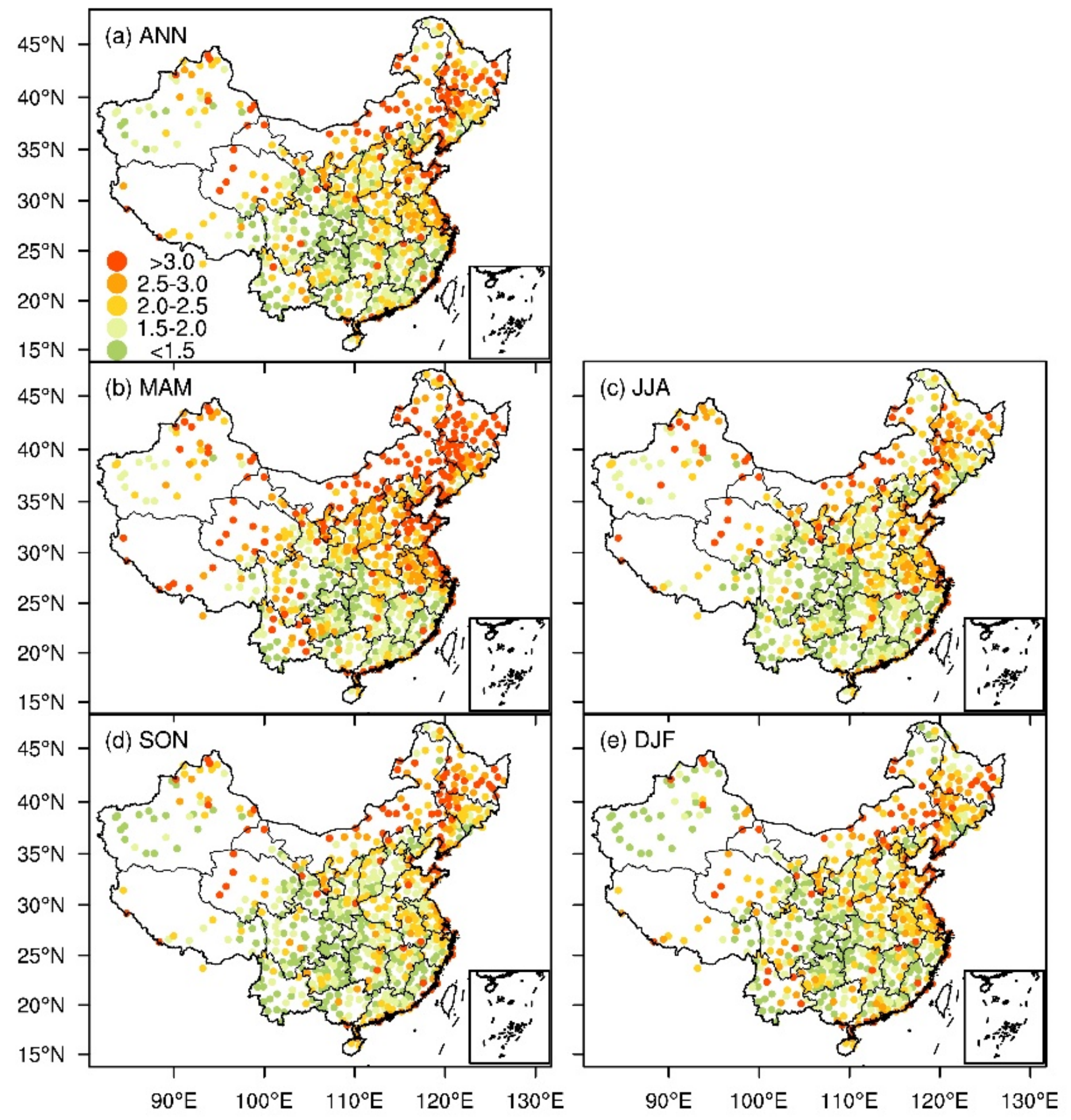

Figure 1

The spatial distributions of the annual (a) and seasonal ((b) Spring, March-May; (c) Summer, JunAugust; (d) Autumn, September-November; (e) Winter, December-February) mean near-surface wind speed (unit: m•s-1) at 679 observation stations in China from 1979 to 2019. 


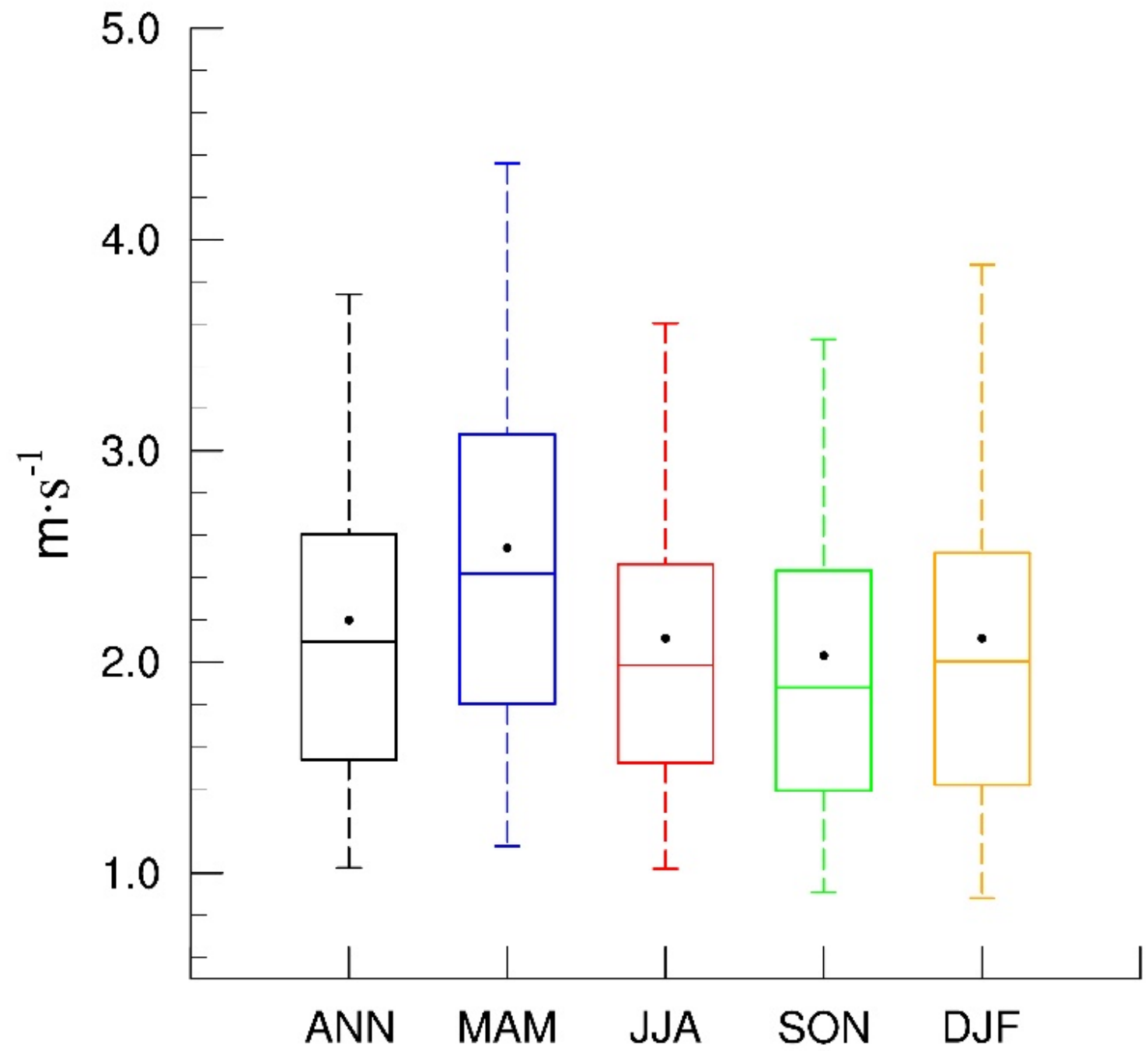

Figure 2

Box plot of the annual and seasonal mean near-surface wind speed for 679 observation stations in 1979-2019. 

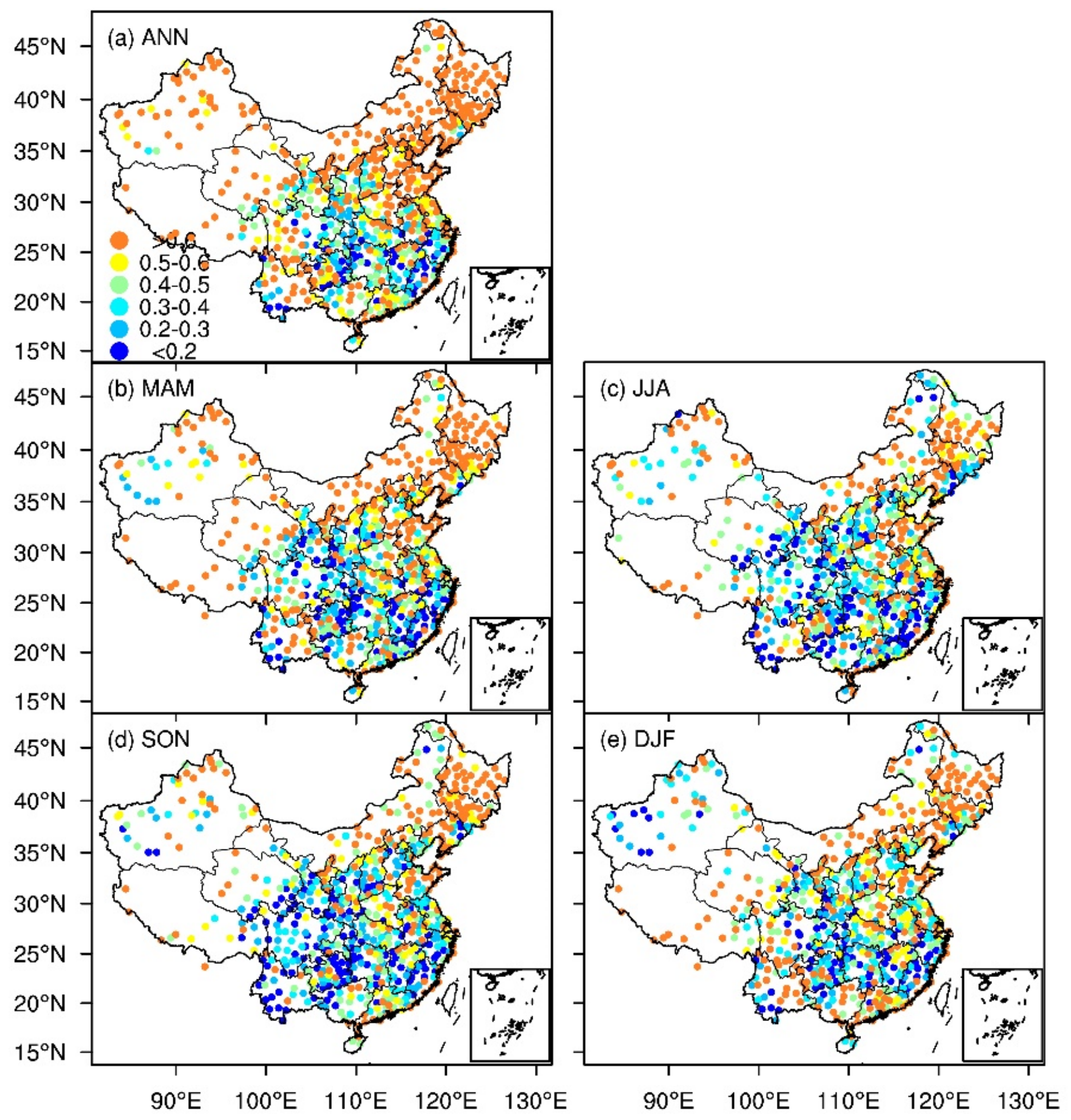

Figure 3

The spatial distributions for the standard deviations of the annual (a) and seasonal ((b) Spring, (c) Summer, (d) Autumn, (e) Winter) near-surface wind speed at 679 observation stations in China from 1979 to 2019. 


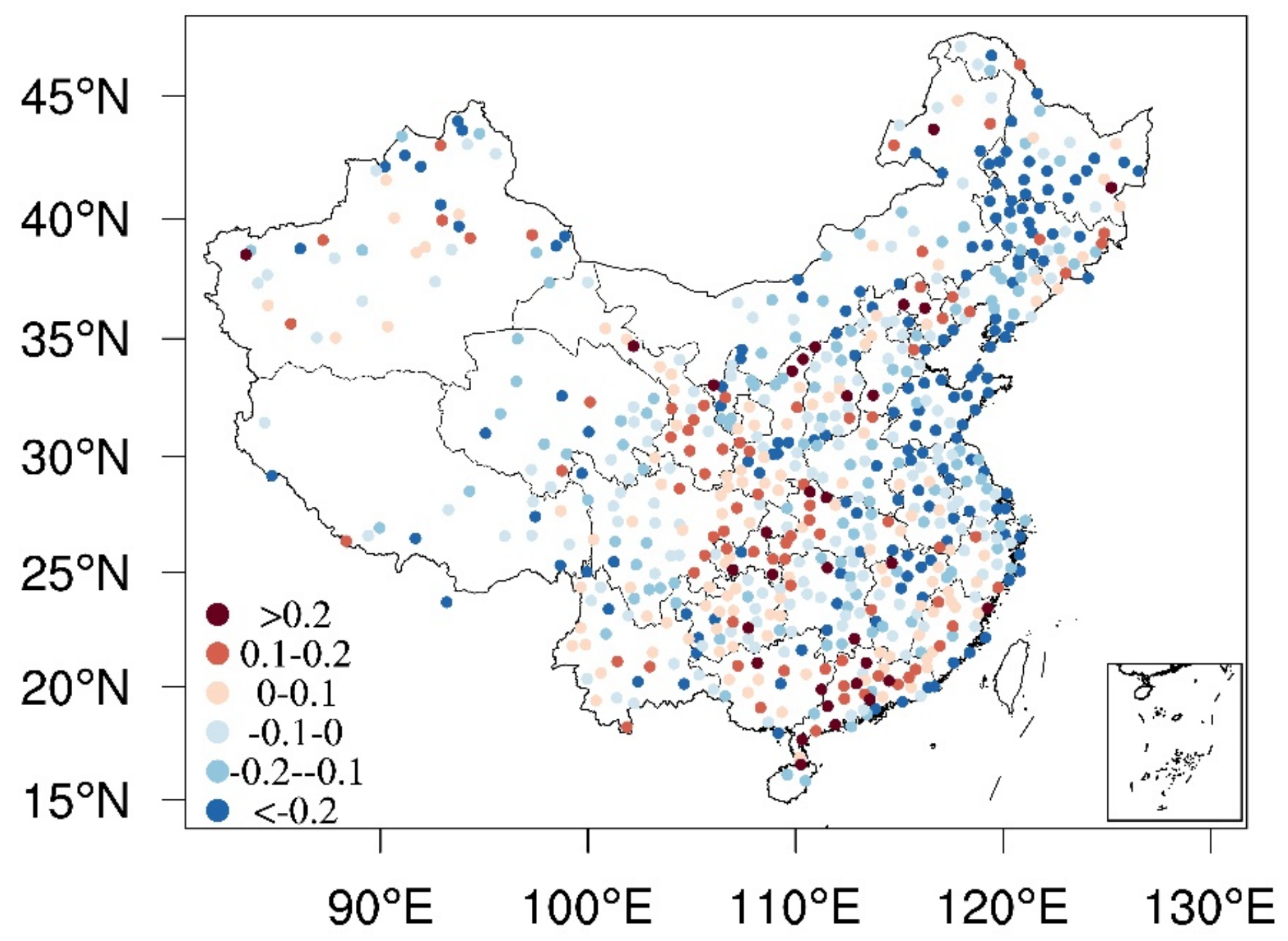

Figure 4

The spatial distribution of the linear trend (unit: $\mathrm{m} \cdot \mathrm{s}-1 \cdot(10 \mathrm{a})-1$ ) for near-surface wind speed in China from 1979 to 2019. 


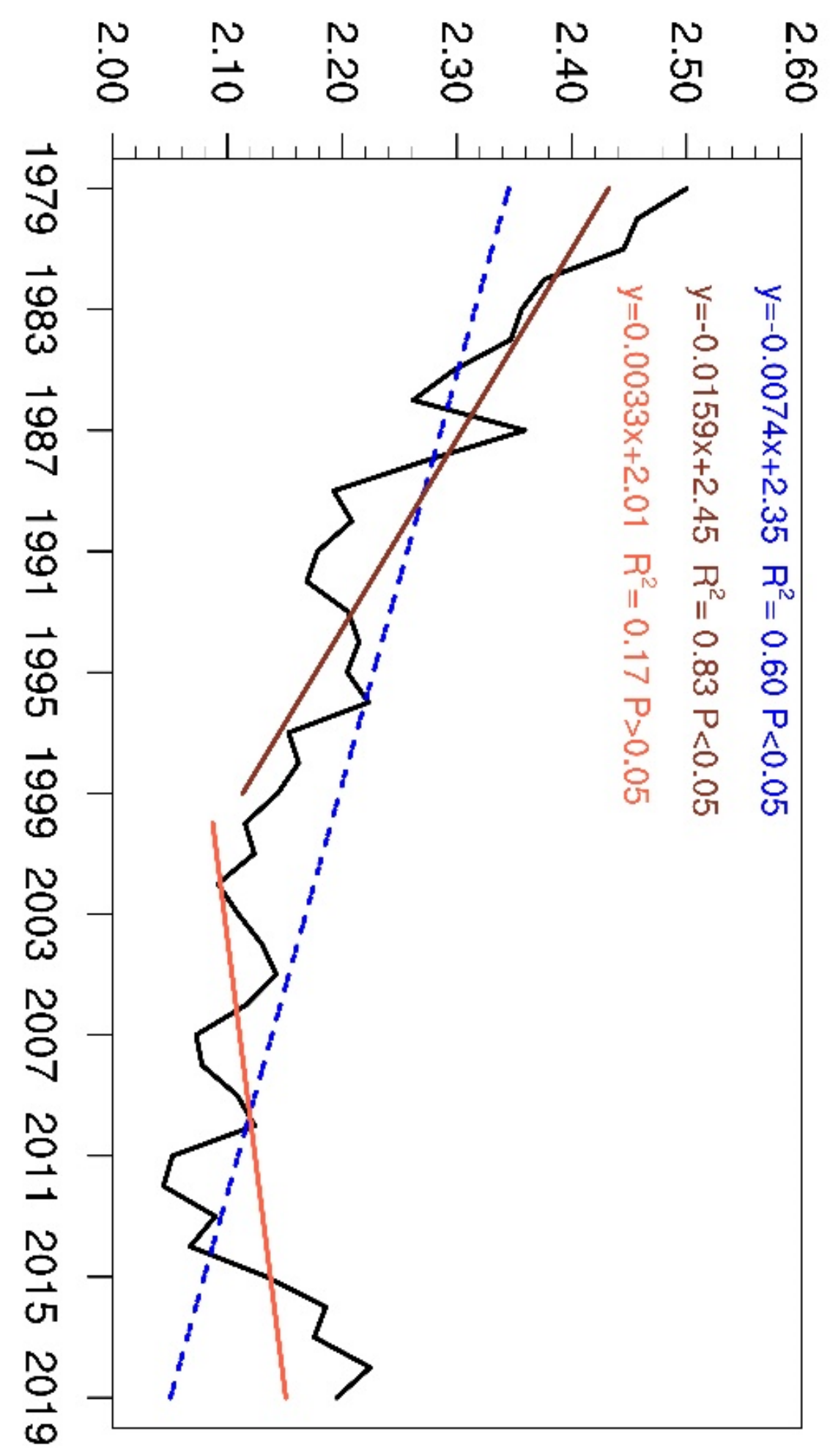

Figure 5

The interannual variation of the mean near-surface wind speed averaged over 679 observation stations in China from 1979 to 2019. 


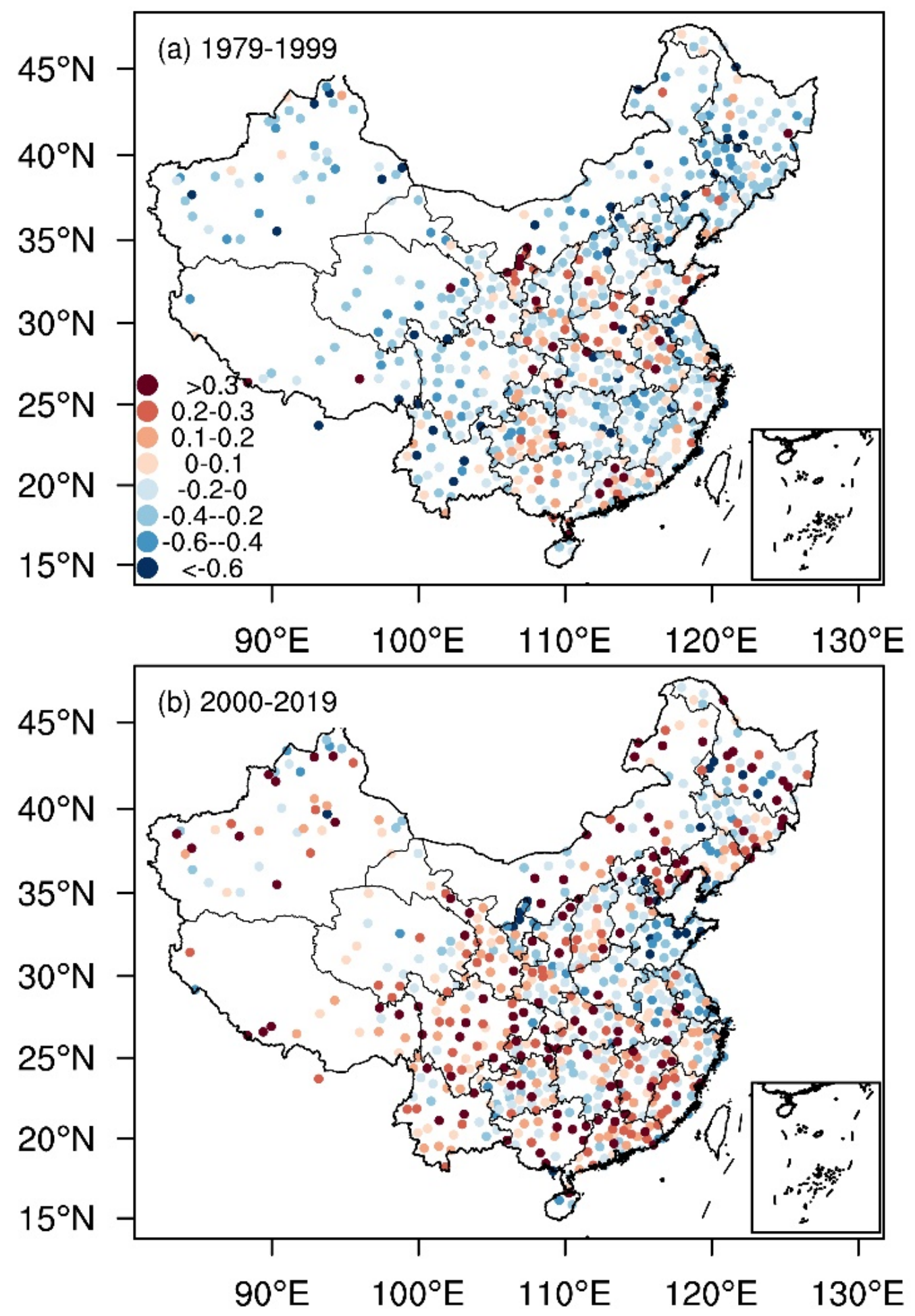

Figure 6

The spatial distributions of the linear trends (unit: $m \cdot s-1 \cdot(10 a)-1$ ) for near-surface wind speed over China in (a) 1979-1999 and (b) 2000-2019. 


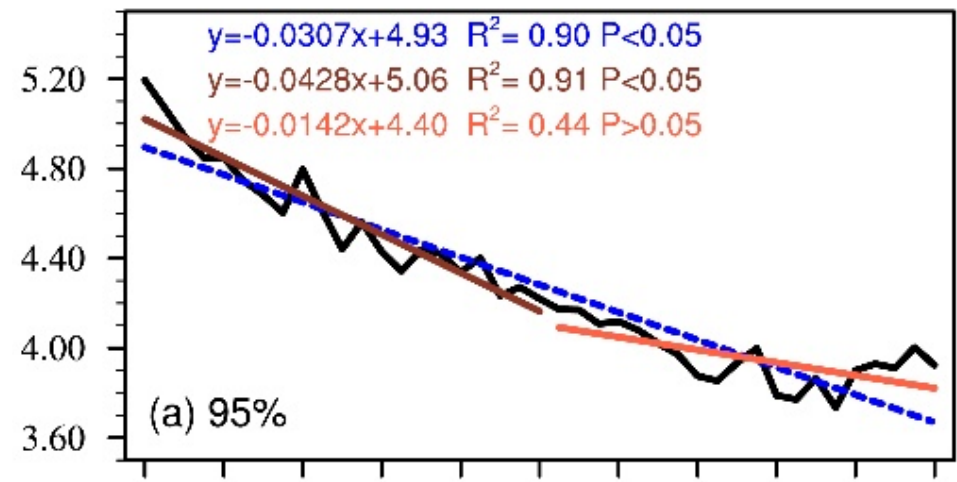

19791983198719911995199920032007201120152019

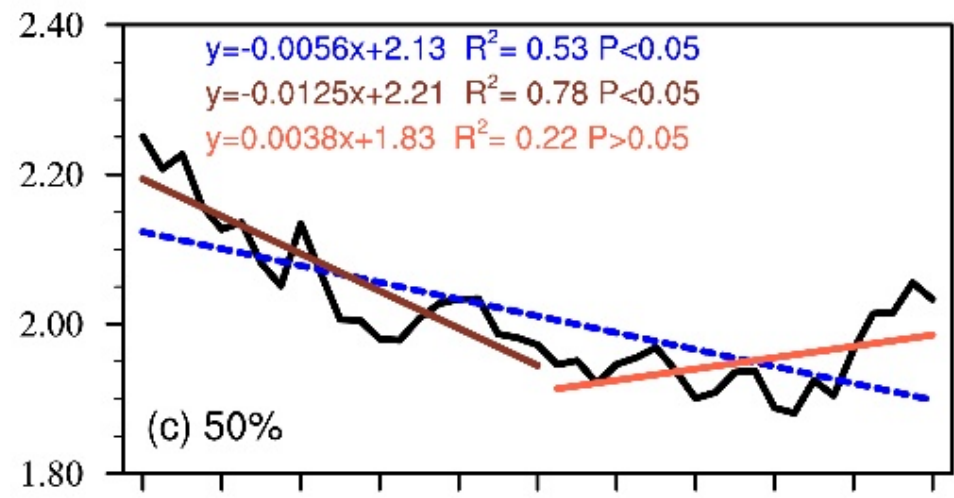

19791983198719911995199920032007201120152019

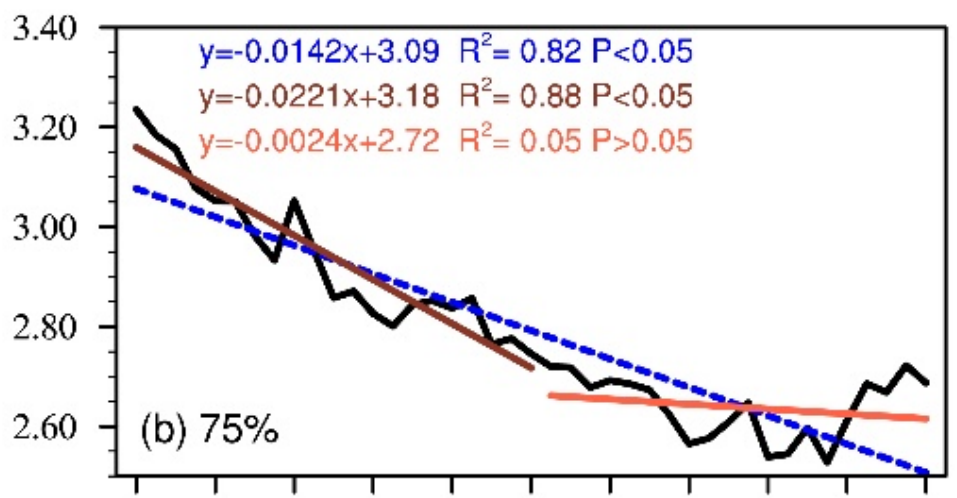

19791983198719911995199920032007201120152019

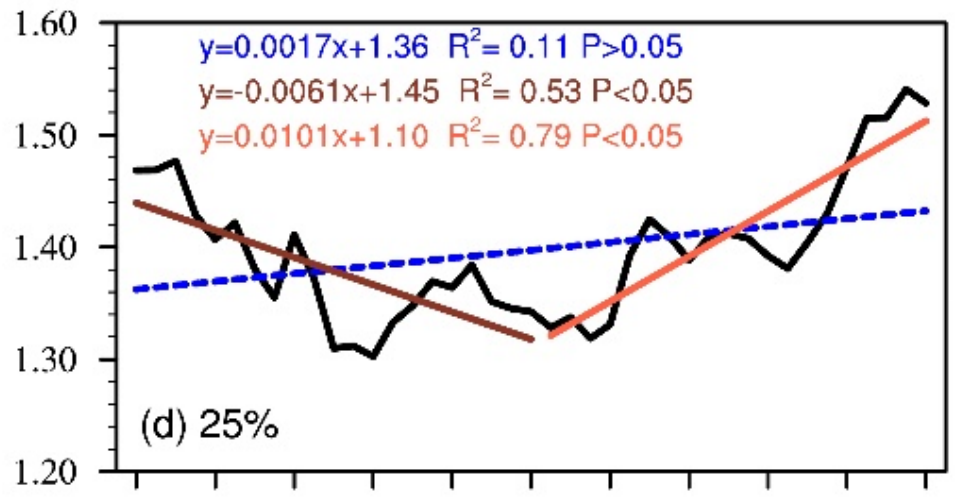

19791983198719911995199920032007201120152019

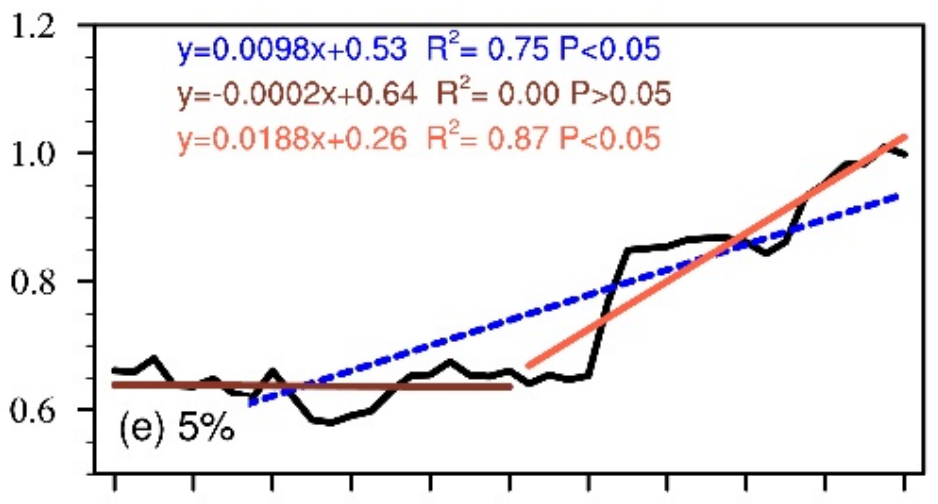

19791983198719911995199920032007201120152019

\section{Figure 7}

The interannual variations (unit: $\mathrm{m} \cdot \mathrm{s}-1$ ) of the mean near-surface wind speed percentiles ((a) 95th percentile, (b) 75th percentile, (c) 50th percentile, (d) 25th percentile, (e) 5th percentile) averaged over 679 observation stations in China from 1979 to 2019. 


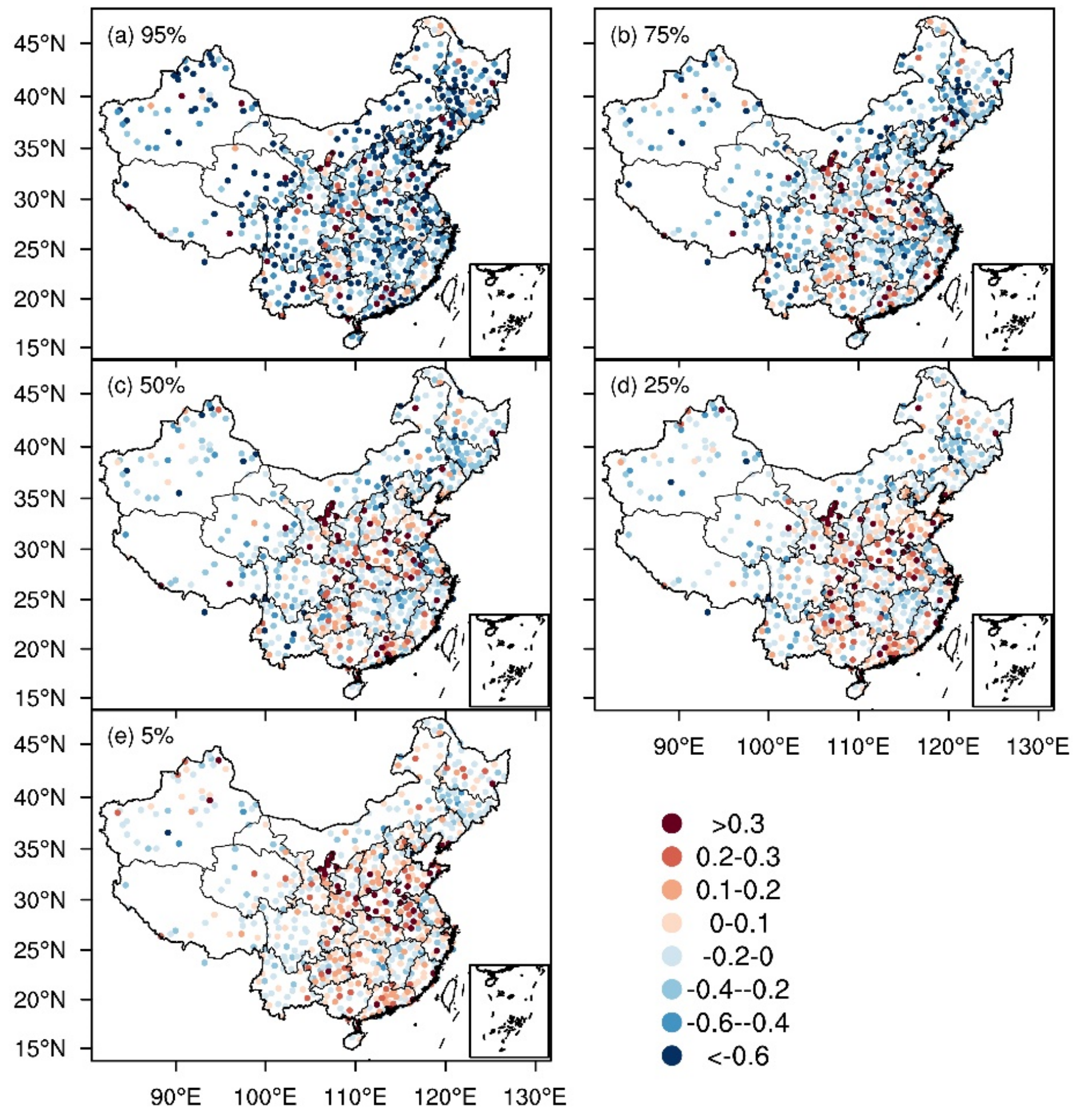

Figure 8

The spatial distributions of the linear trends (unit: $\mathrm{m} \cdot \mathrm{s}-1 \cdot(10 \mathrm{a})-1)$ for the annual near-surface wind speed percentiles ((a) 95th percentile, (b) 75th percentile, (c) 50th percentile, (d) 25th percentile, (e) 5th percentile) at 679 observation stations in 1979-1999. 


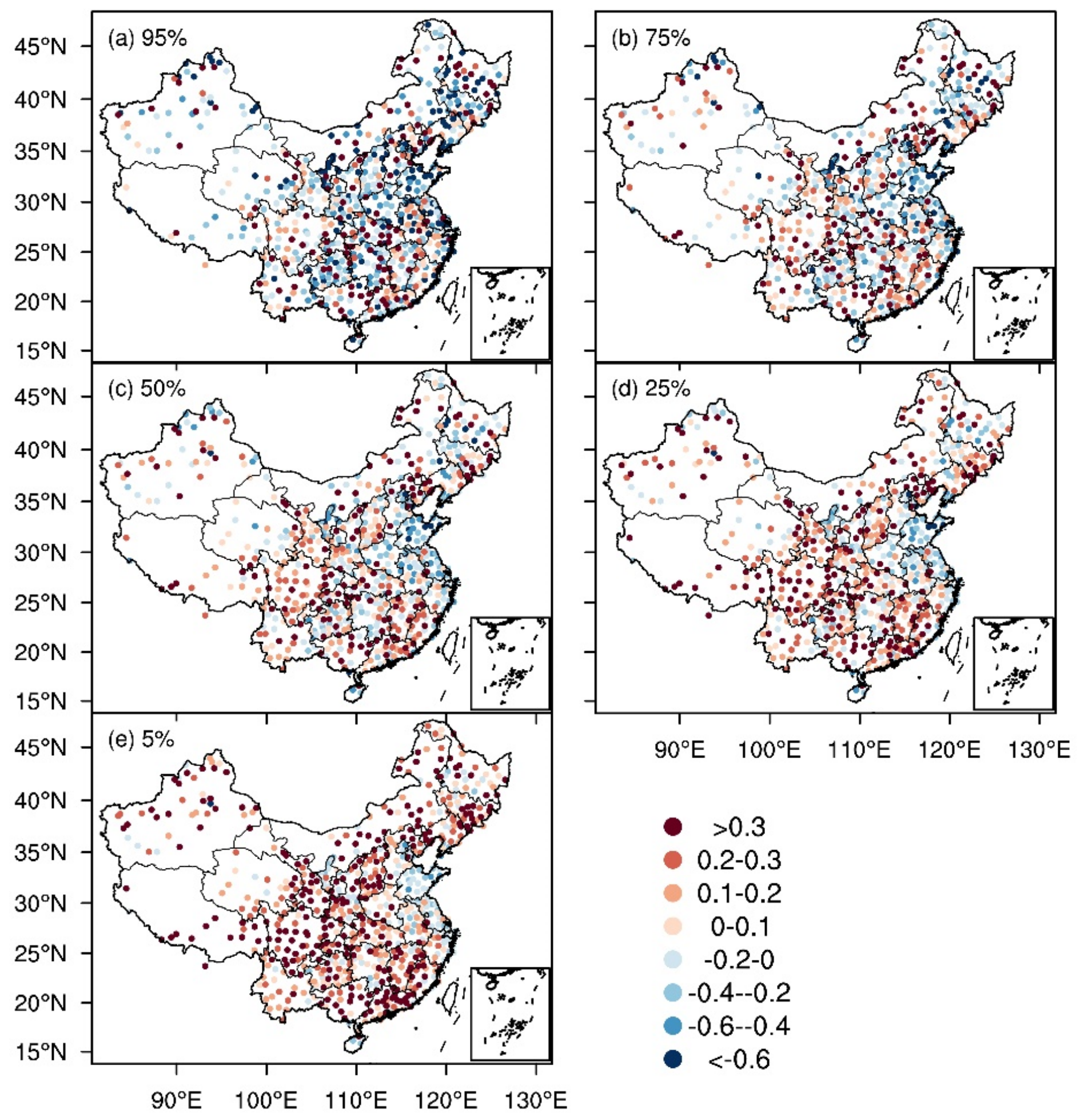

Figure 9

The spatial distributions of the linear trends (unit: $\mathrm{m} \cdot \mathrm{s}-1 \cdot(10 \mathrm{a})-1)$ for the annual near-surface wind speed percentiles ((a) 95th percentile, (b) 75th percentile, (c) 50th percentile, (d) 25th percentile, (e) 5th percentile) at 679 observation stations in 2000-2019. 

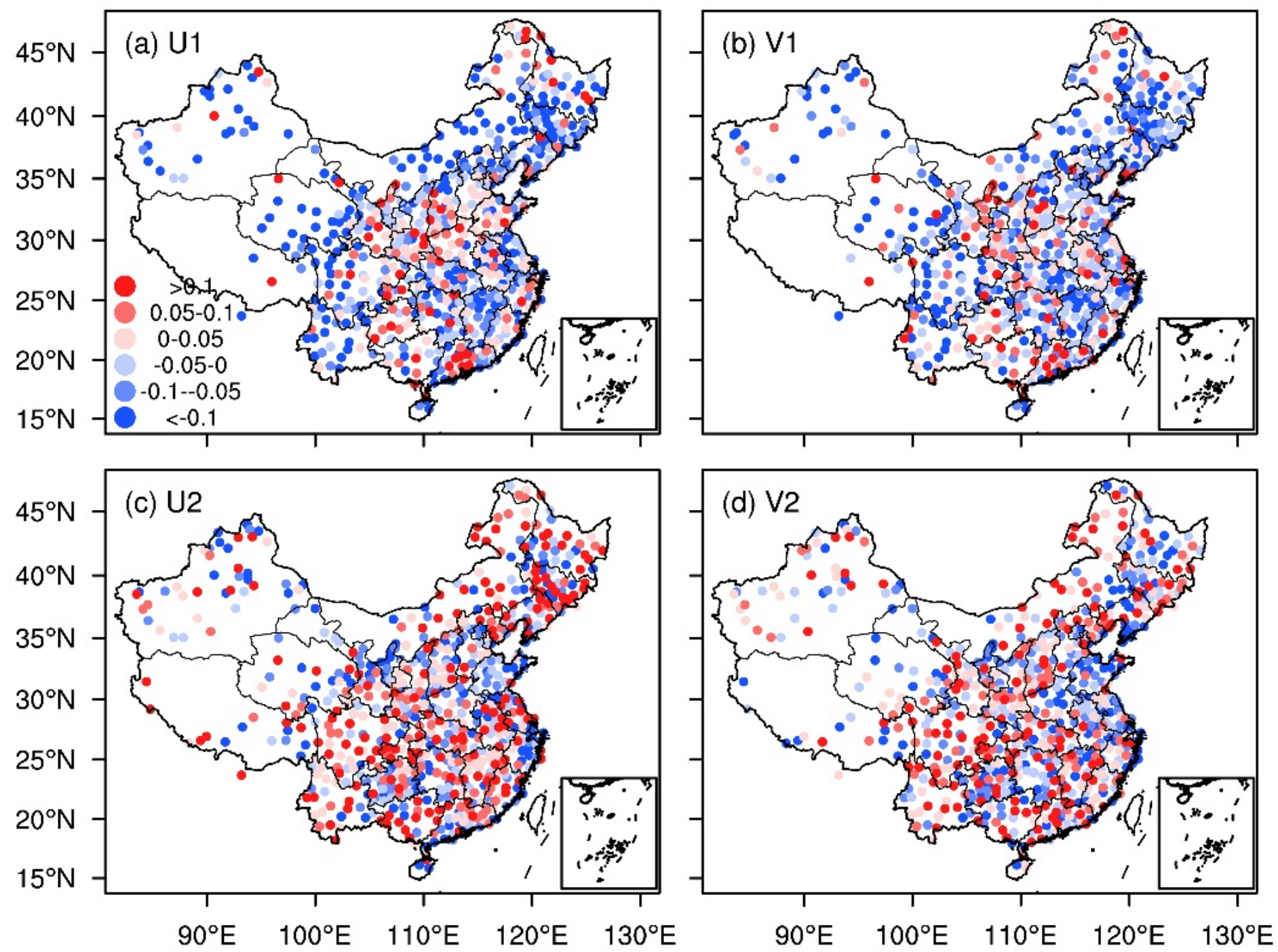

\section{Figure 10}

The spatial distributions of the linear trends (unit: $\mathrm{m} \cdot \mathrm{s}-1 \cdot(10 \mathrm{a})-1$ ) for the absolute $\mathrm{U}(\mathrm{a}$ and $\mathrm{c}$ ) and $\mathrm{V}(\mathrm{b}$ and d) wind components at 679 observation stations in 1979-1999 (a and b) and 2000-2018 (c and d) . 

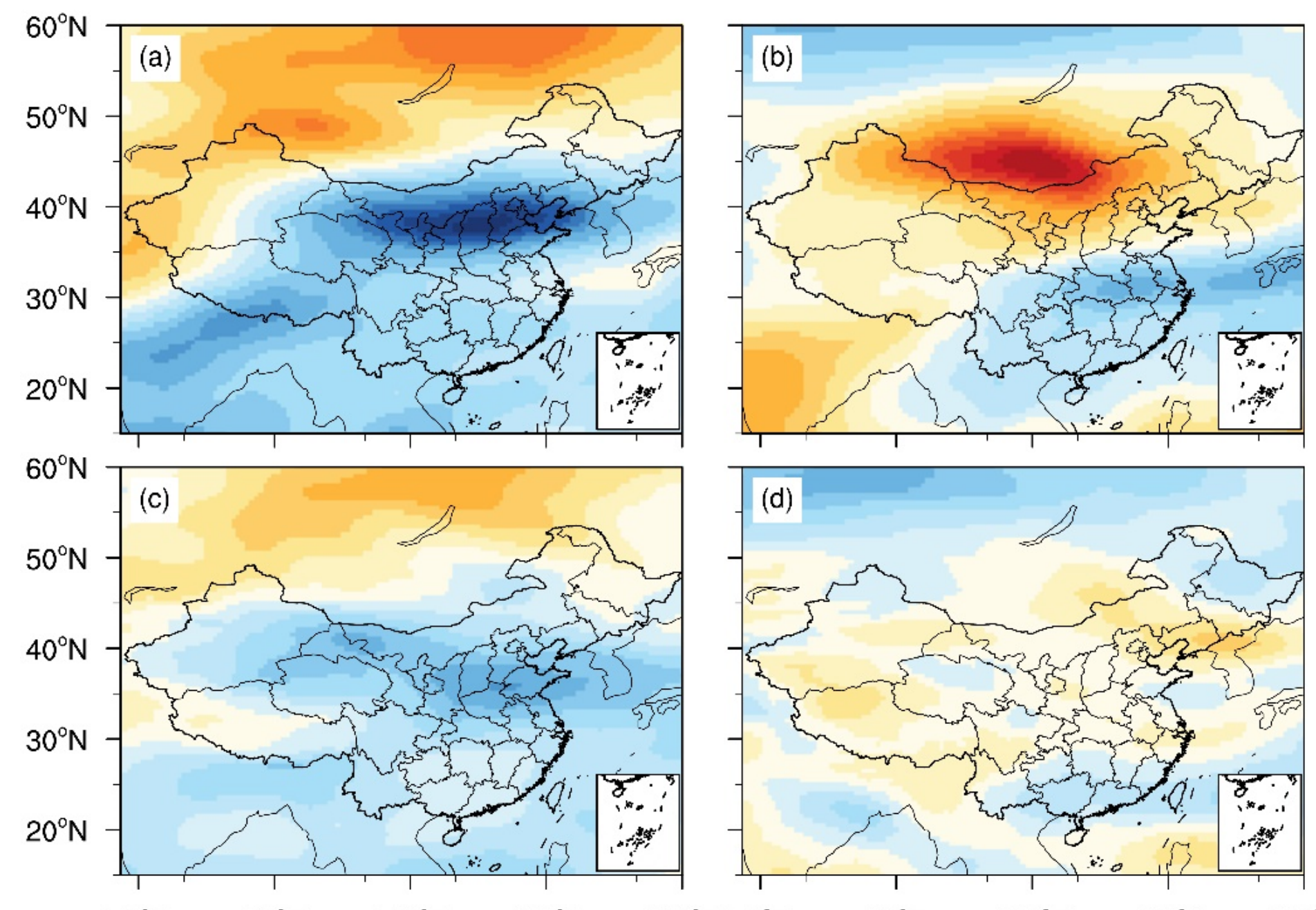

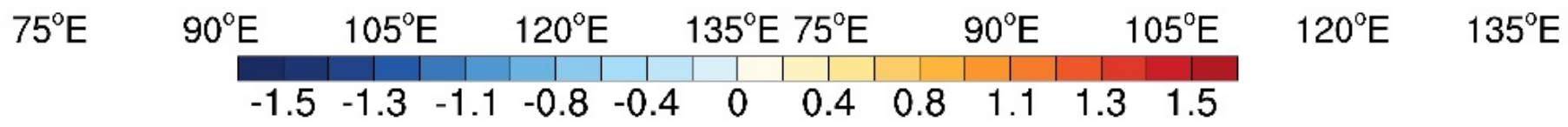

\section{Figure 11}

The spatial distributions of the linear trend (unit: $\mathrm{m} \cdot \mathrm{s}-1 \cdot(10 \mathrm{a})-1$ ) for the zonal wind at $200 \mathrm{hPa}(\mathrm{a}$ and $\mathrm{b}$ ) and $500 \mathrm{hPa}$ (c and d) in 1979-1999 (a and c) and 2000-2018 (b and d). 

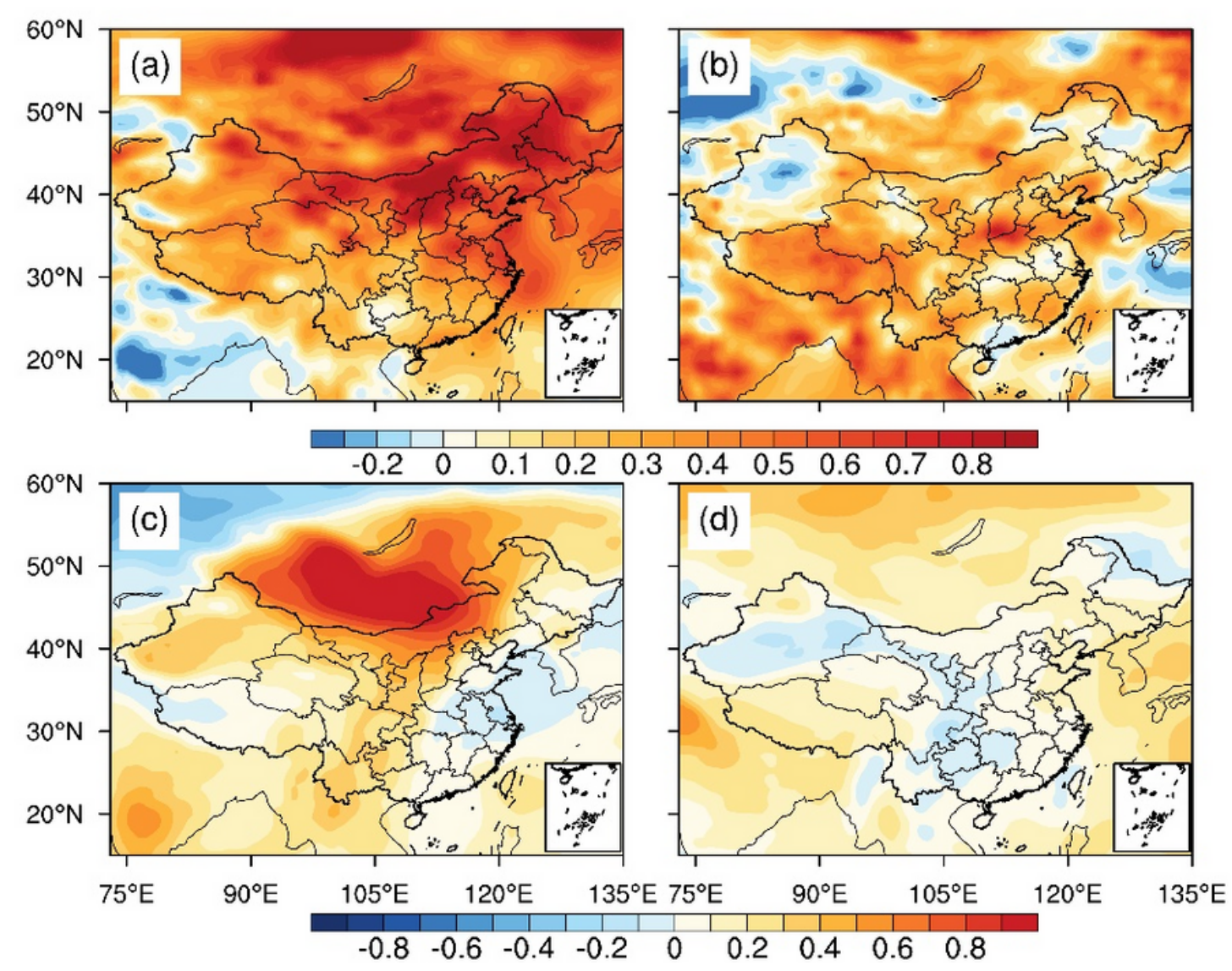

Figure 12

The spatial distributions of the linear trends for the air temperature at $2 \mathrm{~m}$ (a and $\mathrm{b}$, unit: $\left.{ }^{\circ} \mathrm{C} \cdot(10 \mathrm{a})-1\right)$ and surface pressure (c and d, hPa•(10a)-1)) during 1979-1999 (a and c) and 2000-2018 (b and d). 
1979-1999
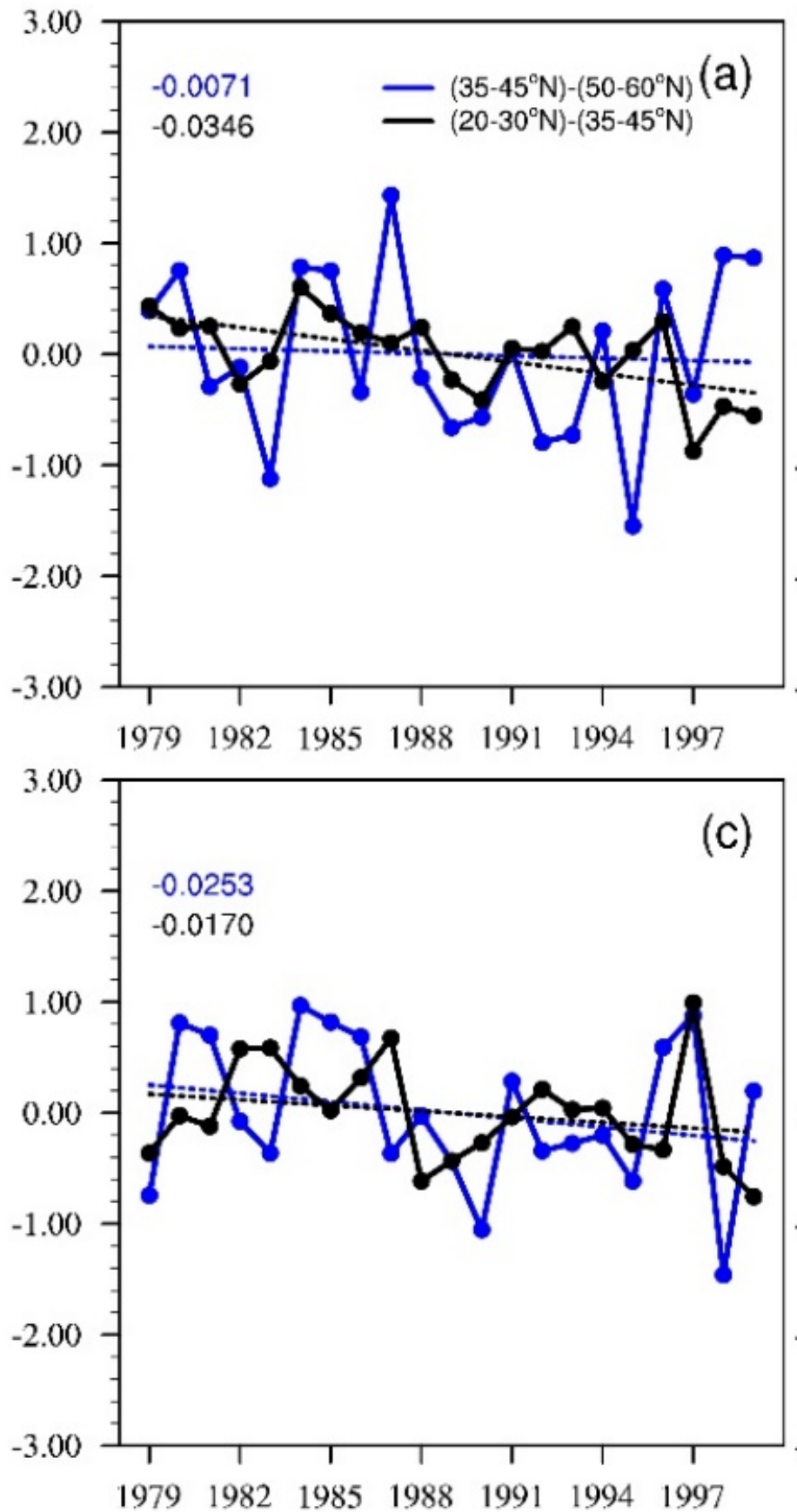

2000-2019
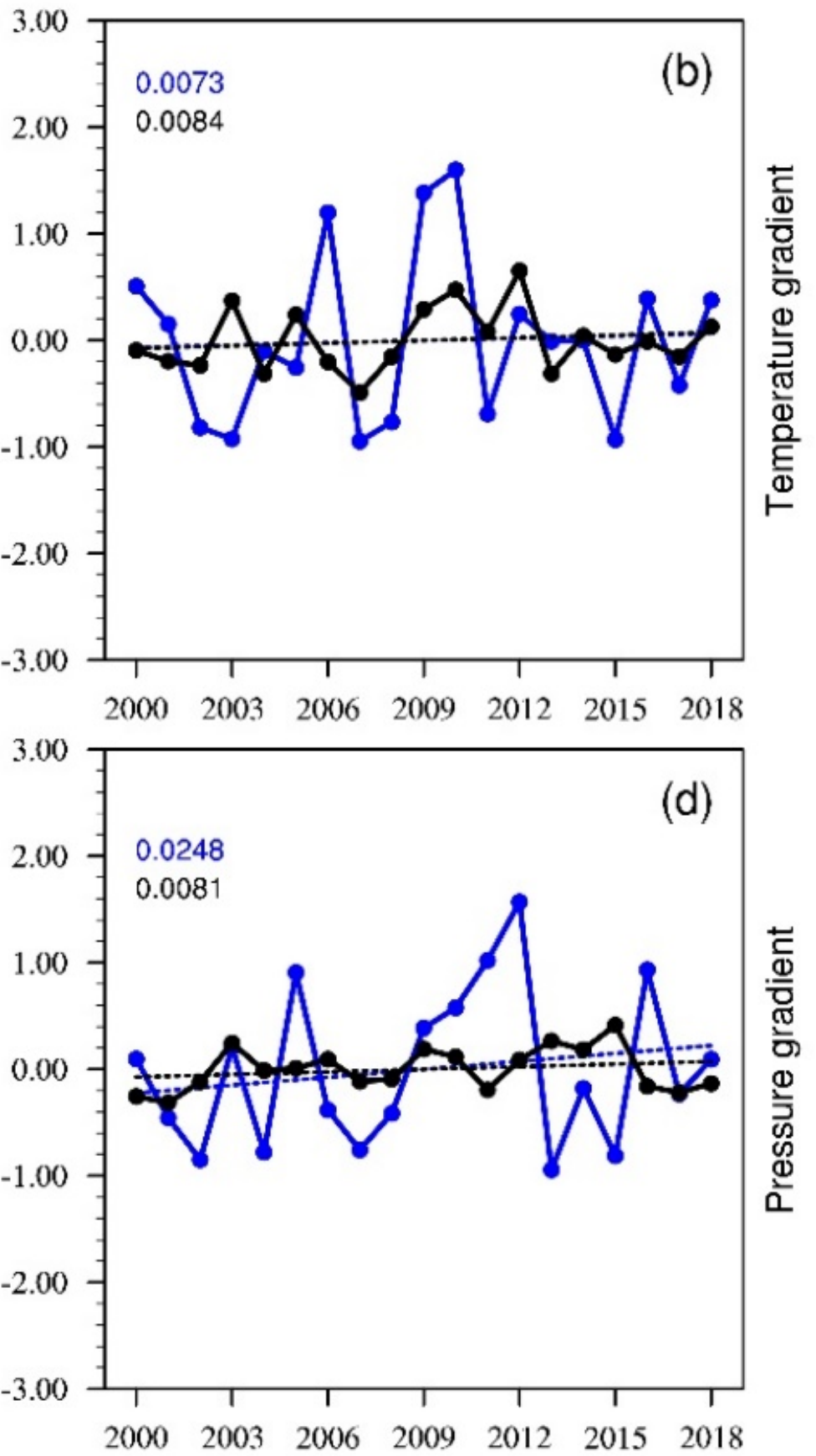

Figure 13

The interannual variations for air temperature ( $a$ and $b$ ) and surface pressure ( $c$ and d) gradients between the low $\left(20^{\circ} \mathrm{N}-30^{\circ} \mathrm{N}\right)$ and middle $\left(35^{\circ} \mathrm{N}-45^{\circ} \mathrm{N}\right)$ latitudes (black line), and between the high $\left(50^{\circ} \mathrm{N}-60^{\circ} \mathrm{N}\right)$ and middle $\left(35^{\circ} \mathrm{N}-45^{\circ} \mathrm{N}\right.$ ) latitudes (blue line) in 1979-1999 (a and c) and 2000-2018 (b and d). 